\title{
Supramolecular Influence on Keto-Enol Tautomerism and Thermochromic Properties of 0 -Hydroxy Schiff Bases
}

\author{
Marija Zbačnik,* Branko Kaitner
}

\author{
Department of Chemistry, Faculty of Science, University of Zagreb, Horvatovac 102a, HR-10000 Zagreb, Croatia \\ * Corresponding author's e-mail address: mzbacnik@chem.pmf.hr
}

RECEIVED: April 4, 2016 * REVISED: May 17, 2016 * ACCEPTED: May 20, 2016

Abstract: This work presents a study on thermo-optical properties of three Schiff bases (imines) in the solid state. The Schiff bases were obtained by means of mechanochemical synthesis using monosubstituted o-hydroxy aromatic aldehydes and monosubstituted aromatic amines. The keto-enol tautomerism and proton transfer via intramolecular $\mathrm{O} \cdots \mathrm{N}$ hydrogen bond of the reported compounds was found to be influenced more by supramolecular interactions than by a temperature change. All products were characterised by powder X-ray diffraction (PXRD), FT-IR spectroscopy, thermogravimetric (TG) analysis and differential scanning calorimetry (DSC). Molecular and crystal structures of compounds 1,2 and $\mathbf{3}$ were determined by single crystal X-ray diffraction (SCXRD). The molecules of 1 appear to be present as the enol-imine, the molecules of 2 as the keto-amine tautomer and the molecules of 3 exhibit keto-enol tautomeric equilibrium in the solid state. An analysis of Cambridge structural database (CSD) data on similar imines has been used for structural comparison.

Keywords: keto-enol tautomerism, Schiff bases, mechanochemistry, thermochromism.

\section{INTRODUCTION}

$\boldsymbol{N}$ -SUBSTITUTED imines or Schiff bases can be easily synthesized by condensation of aldehydes (or ketones) and primary amines. ${ }^{[1]}$ They are a very good class of organic compounds for the investigation of faster and ecologically and economically more acceptable ways of preparation. ${ }^{[2,3]}$ Many Schiff bases have been synthesized in such manner by grinding using a mortar and pestle or ball mill grinders or merely by putting the reactants in close contact and leaving the reaction mixture to age. ${ }^{[4-8]}$

The physico-chemical, biological, pharmacological properties of $\mathrm{N}$-substituted imines and their metal complexes are well recognized reasons of a widespread and continuous strong interest in their investigation. ${ }^{[9,10]}$ In this big class of compounds, o-hydroxy aromatic imines are drawing special attention for many years. Their optical properties in the solid state can be switched by various stimuli, for example temperature change in thermochromic or by changing the wavelength of irradiation in photochromic Schiff bases. ${ }^{[11]}$ The microscopic reasons of such macroscopic properties are still under investigation, ${ }^{[7,8,12-19]}$ and this work is one of them. There are three described mutually dependant reasons for such behaviour in the solid state: proton transfer via intramolecular $\mathrm{O} \cdots \mathrm{N}$ hydrogen bonds and thus the change of the tautomeric form, ${ }^{[12-17]}$ the contribution of fluorescence and not only of light absorption as a consequence of the tautomeric change and the change in molecular geometry. ${ }^{[18]}$ The scientists are still trying to either reaffirm the mentioned reasons or to find imines in which the reasons cannot be strictly determined but they do show such chromic change. ${ }^{[7,8,18-23]}$

In this work, we report both the mechanochemical synthesis and the investigation of structurethermochromism correlation of three Schiff bases (Scheme 1) derived from three aromatic aldehydes $o$-vanillin (ovan), o-hydroxysalicylaldehyde (oOH) and $p$-hydroxysalicylaldehyde (pOH) and three aromatic amines - 2-amino-4-methylphenol (2a4mp), 3-aminoacetophenone (3aa) and 4-aminoacetophenone (4aa). The aldehydes and amines were selected according to the 


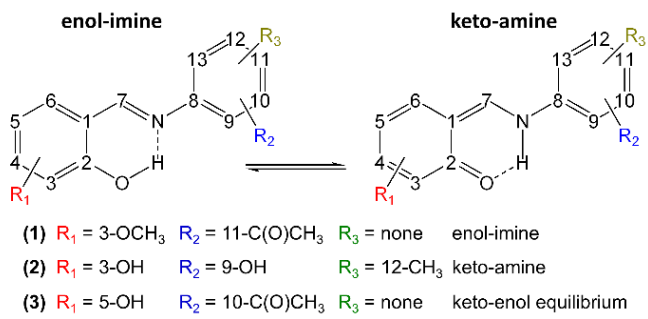

Scheme 1. Molecular structures of compounds 1, 2 and 3 with the numbering scheme.

possibility of their substituents to participate as acceptors and/or donors in $\mathrm{H}$-bonds. We have succeeded to prepare one Schiff base in enol-imine tautomeric form, compound $\mathbf{1}$, one in keto-amine form, compound $\mathbf{2}$, and one which exhibits keto-enol equilibrium affected by temperature change in the solid state, compound $\mathbf{3}$.

\section{EXPERIMENTAL}

Details for synthetic procedures, PXRD, SCXRD, FT-IR, TG and DSC characterization are given in ESI.

\section{Cambridge Structural Database ${ }^{[24]}$ (CSD) Investigations}

The purpose of the search was to find out how many reported Schiff bases derived from ovan, $\mathbf{O O H}$ and $\mathbf{p O H}$ are in keto-amine and/or in enol-imine tautomeric form in the solid state and to use the data to compare the crucial bond lengths and values of dihedral angles $(\Phi)$ with the values of compounds 1-3 and not only to use the criteria proposed by Allen et.al. obtained on data reported until 1987.[25] A study of the CSD Version 5.37 (November 2015 release, February 2016 Update) ${ }^{[24]}$ was done using ConQuest ${ }^{[26]}$ Version 1.18 and the data analysis was done using Mercury 3.8. ${ }^{[27]}$ The search was made with the filtering criteria that the entries had to have their 3-D coordinates determined.

\section{Synthesis and Characterization}

In all three cases $1 \mathrm{mmol}: 1 \mathrm{mmol}$ stochiometric ratio of aldehyde and amine was used in order to obtain the Schiff base. Syntheses were performed at room temperature (RT) and at 40-60\% relative humidity. Bulk products of syntheses and recrystallization were characterized by means of PXRD, DSC, TGA and FT-IR. The structural investigations were performed at RT (298 K) and LT (110 K).

Compound 1 (1-\{4-[(2-hydroxy-3-methoxy-benzylidene)-amino]-phenyl\}-ethanone) was obtained from ovan and 4aa, compound 2, (2-hydroxy-6-[(2-hydroxy-5-methylphenylamino)-methylene]-cyclohexa-2,4-dienone), from $\mathbf{O O H}$ and $2 \mathrm{a} 4 \mathrm{mp}$ and compound 3 (1-\{3-[(2,5-dihydroxybenzylidene)-amino]-phenyl\}-ethanone was obtained from pOH and 3aa.
Neat grinding (NGam) of solid reactants (ovan and 4aa) in an agate mortar lead first to a moist paste-like reaction mixture and then to an orange powder after three minutes (Figure S1a)). The paste-like intermediate phase is expected in this case since the melting points of both reactants $\left(40-42{ }^{\circ} \mathrm{C}\right.$ for ovan and $103-107^{\circ} \mathrm{C}$ for 4aa) are low enough for such behaviour and reaction pathway to take place. ${ }^{[7,28-33]}$ However the conversion to compound 1 was incomplete according to the PXRD data as can be seen in Figure 1 (left). For that reason, the reaction was repeated in a mortar by means of liquid-assisted grinding (LAGam) using $20 \mu \mathrm{L}$ acetonitrile (MeCN) yielding in complete conversion of reactants into compound 1.

Neat grinding of $\mathrm{OOH}$ and $2 \mathrm{a} 4 \mathrm{mp}$ in a mortar for 11 minutes did not give any change in colour or aggregation state of the reaction mixture and for that reason a catalytic amount $(20 \mu \mathrm{L})$ of tetrahydrofuran (thf) was added (Figure S2a)). In three minutes of further grinding an orange powder was obtained. PXRD experiments have shown that a complete conversion of reactants to product, compound 2, was achieved as can be seen in Figure 1 (middle). Since the melting points of both reactants are well above $100{ }^{\circ} \mathrm{C}\left(104-108^{\circ} \mathrm{C}\right.$ for $\mathbf{0 O H}$ and $133-136^{\circ} \mathrm{C}$ for $2 \mathrm{a} 4 \mathrm{mp}$ ) the formation of a liquid or a paste was not expected. ${ }^{7,28-33]}$

The reaction mixture starts to change its colour already after one minute of NGam of $\mathbf{p O H}$ and 3aa (Figure $\mathrm{S} 3 \mathrm{a})$ ). As expected from the values of the melting points of reactants $\left(97-99{ }^{\circ} \mathrm{C}\right.$ for $\mathrm{pOH}$ and $94-98{ }^{\circ} \mathrm{C}$ for 3aa) the route of conversion of reactants is via a paste-like intermediate phase. ${ }^{[7,27-32]}$ The paste forms slowly and starts to solidify after about 13 minutes of grinding. Finally, a red powder of compound 3 was obtained after 14 minutes of grinding and there were no traces of reactants in it, revealed by PXRD experiments (Figure 1 (right)).

\section{Structural Investigations}

PXRD experiments were performed on a PHILIPS PW 1840 $\mathrm{X}$-ray diffractometer with $\mathrm{Cu} K_{\alpha 1}(1.54056 \AA$ ) radiation at $40 \mathrm{~mA}$ and $40 \mathrm{kV}$. The scattered intensities were measured with a scintillation counter. The angular range $(2 \theta)$ was from 5 to $45^{\circ}$ with steps of $0.02^{\circ}$, and the measuring time was $0.5 \mathrm{~s}$ per step. The data collection and analysis were performed using the program package Philips X'Pert. SCXRD experiments were performed at $298 \mathrm{~K}$ (RT) and $110 \mathrm{~K}$ (LT) in order to explore thermochromic behaviour of these compounds using an Oxford Diffraction Xcalibur Kappa CCD $\mathrm{X}$-ray diffractometer with graphite-monochromated Mo $K_{\alpha}$ $(\lambda=0.71073 \AA$ ) radiation (for details see the ESI).

\section{Thermal Analysis}

The measurements were performed on a Mettler Toledo DSC823e and on a Mettler Toledo TGA/SDTA 851 module. 

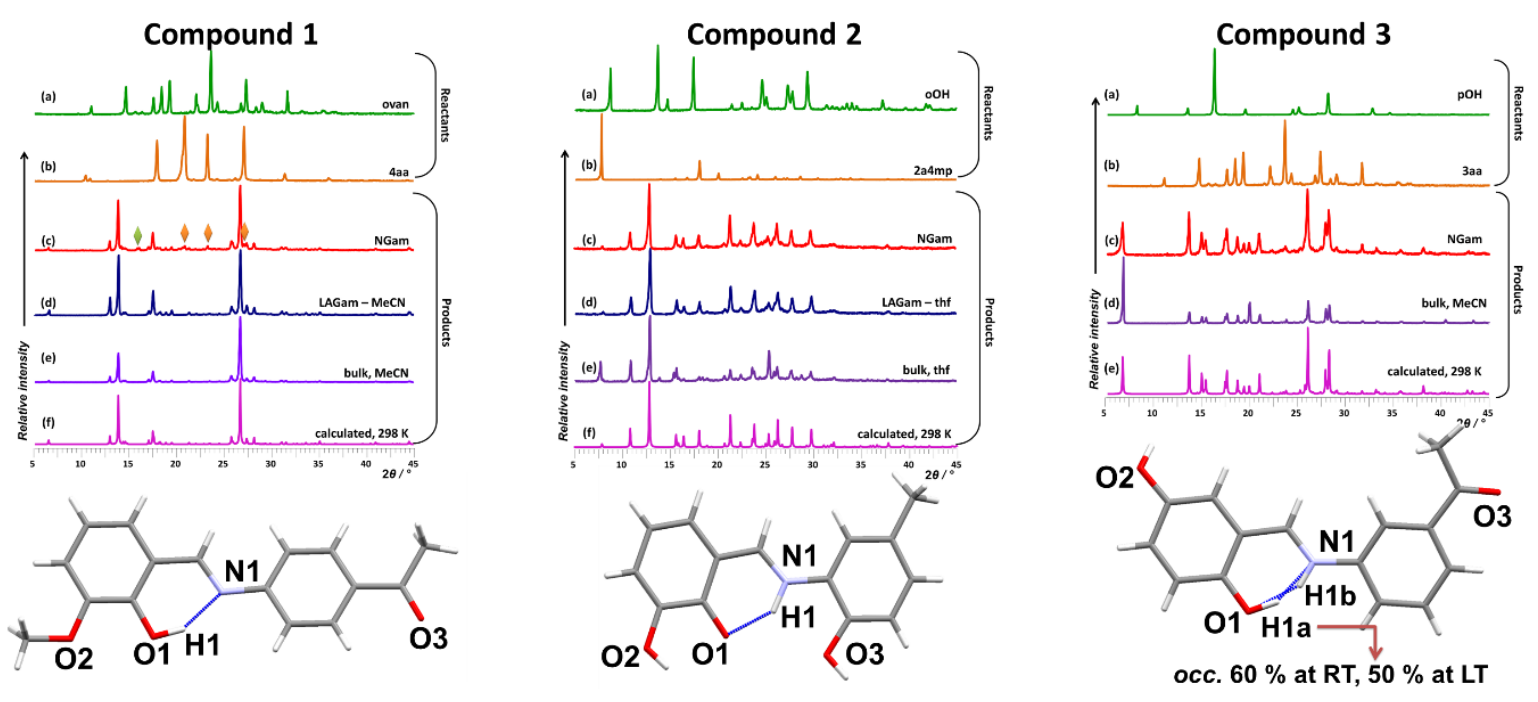

Figure 1. Molecule of compound 1 (bottom) and (top) PXRD patterns of (a) ovan; (b) 4aa; (c) 1 prepared by NG (green and orange rhombi indicating unreacted reactants diffraction maxima); (d) 1 prepared by LAG; (e) 1 obtained by evaporation of $\mathrm{MeCN}$; and (f) the calculated pattern of compound 1. Molecule of compound 2 (bottom) and (top) PXRD patterns of (a) $\mathrm{OOH}$; (b) 2a4mp; (c) 2 prepared by NG; (d) 2 prepared by LAG; (e) 2 obtained by evaporation of thf; and (f) the calculated pattern of compound 2. Molecule of compound 3 (bottom) and (top) PXRD patterns of (a) pOH; (b) 3aa; (c) 3 prepared by NG; (d) 3 obtained by evaporation of $\mathrm{MeCN}$; and (e) the calculated pattern of compound 3.

The data was analysed using STARe Software V10.00., Mettler-Toledo AG, 1993-2011.

\section{Spectroscopic Study on Recrystallized Material}

Infrared spectra were recorded on a PerkinEImer Spectrum Two FTIR spectrophotometer using the $\mathrm{KBr}$ pellet method. For details see ESI.

\section{RESULTS AND DISCUSSION}

\section{CSD $^{[24]}$ Data Analysis}

Data obtained by means of the search are comprised in Table S6 and the structural motifs used for CSD $^{[24]}$ search are shown in top row of the table (see ESI).

The search revealed that there are 96 entries in total, 47 entries that correspond to Schiff bases derived from ovan, 40 entries for ones derived from $\mathbf{o O H}$ and 9 for $\mathbf{p O H}$. The scatterplot of $d(\mathrm{C} 7-\mathrm{N} 1)$ vs. $d(\mathrm{C} 2-\mathrm{O} 1)$ of all data obtained by the CSD search is shown in Figure 2 while Figure 3 shows a diagram of incidence of imines being (non)planar e.g. having the dihedral angle $\leq 25^{\circ} \geq$.

Using the data reported by Allen et. al. ${ }^{[25]}$ (Table S7 in ESI) and the data obtained by the search we can conclude that the imines derived from ovan (Figure 2, red dots) and pOH (Figure 2, green dots) are mostly in enol-imine tautomeric form in the solid state. However, the Schiff bases derived from $\mathrm{OOH}$ (Figure 2, blue dots) in most cases have intermediary values of $\mathrm{C} 2-\mathrm{O} 1$ and $\mathrm{C} 7-\mathrm{N} 1$ bond lengths. According to the bond length criterion, compound $\mathbf{1}$ is a pure enol-imine (and is so) while compound $\mathbf{2}$ and $\mathbf{3}$ should exhibit keto-enol tautomerism in the solid state. Such behaviour was found only for compound $\mathbf{3}$ and compound $\mathbf{2}$ is a keto-amine, opposite than one can expect and conclude from Figure 2.

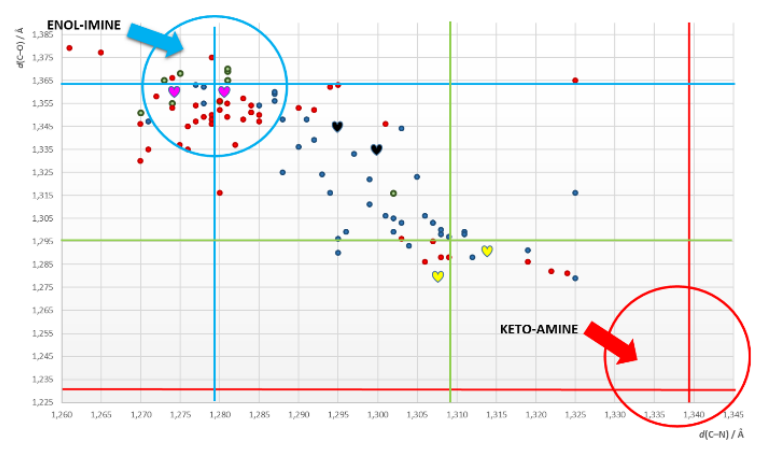

Figure 2. Scatterplot of $d(\mathrm{C} 7-\mathrm{N} 1)$ vs. $d(\mathrm{C} 2-\mathrm{O} 1)$ of data obtained by the CSD ${ }^{[24]}$ search. Red dots - ovan imines; blue dots - oOH imines; green dots - pOH imines; pink hearts compound 1, yellow hearts - compound 2; black hearts compound 3; blue line - limiting values of $d(\mathrm{C} 7-\mathrm{N} 1)$ and $d(C 2-01)$ for an enol-imine, ${ }^{[25]}$ red line - limiting values of $d(\mathrm{C} 7-\mathrm{N} 1)$ and $d(\mathrm{C} 2-\mathrm{O} 1)$ for a keto-amine, ${ }^{[25]}$ green line average values of $d(\mathrm{C} 7-\mathrm{N} 1)$ and $d(\mathrm{C} 2-\mathrm{O} 1) .{ }^{[25]}$ 
In all three cases of $o$-hydroxy imines reported here, the dihedral angles between aromatic subunits are well under $25^{\circ}$ (Table 1 ), the value which has been declared in literature and several times disproved as an important criterion for thermochromic behaviour. ${ }^{[12-23]}$ A molecular overlay of molecules of all three Schiff bases is given in Figure $3 \mathrm{~b}$ and shows the small deviation of the molecules from planarity. The influence of temperature on the planarity of these three imines is neglectable.

Most of the imines found reported in the CSD are planar (Table S6) and as such should show thermochromic properties, but we emphasize once again that this criterion should be taken prudently into consideration. Once again, we prove here that though the dihedral angles in molecules of $\mathbf{1 - 3}$ are well $<25^{\circ}$, compound $\mathbf{3}$ is not thermochromic.

\section{Structural Analysis}

Single crystals suitable for SCXRD experiments were obtained by slow evaporation of solvent (MeCN for $\mathbf{1}$ and $\mathbf{2}$ and thf for 3). General and crystallographic data for all three compounds are given in ESI (Tables S2-S4) and CCDC 1442712-1442714 contain crystallographic data for this paper. Table 1 comprises data on $\mathrm{C} 7-\mathrm{N} 1$ and $\mathrm{C} 2-\mathrm{O} 1$ bond
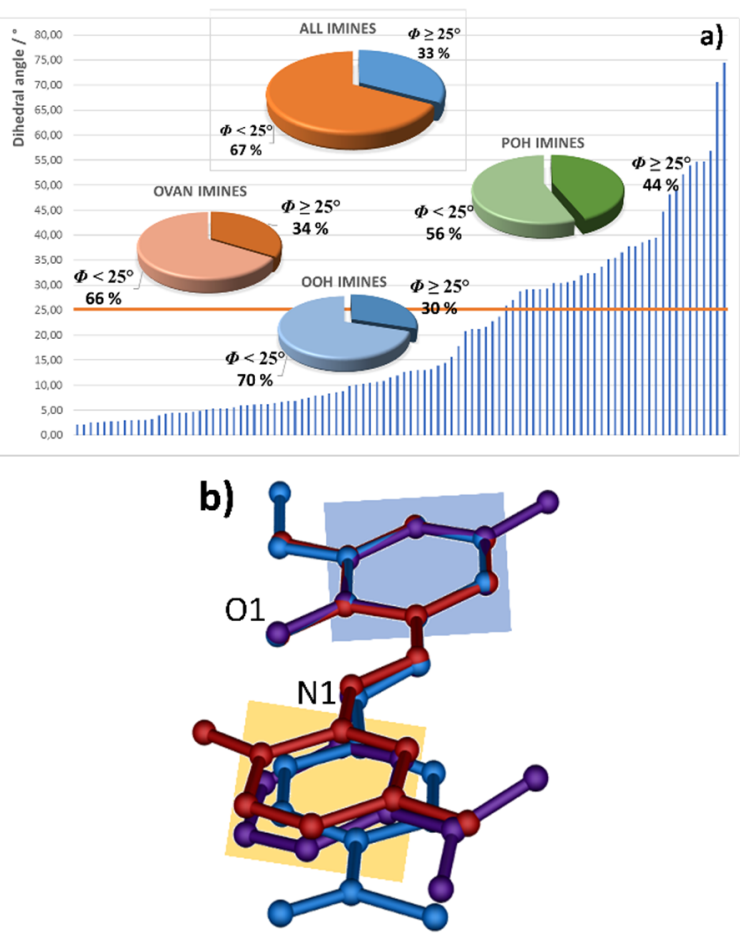

Figure 3. a) A diagram of incidence of imines being (non)planar e.g. having the dihedral angle $\leq 25^{\circ} \geq$; b) a molecular overlay of 1 (blue), 2 (red), and 3 (purple) - blue and yellow squares represent planes in which the aromatic moieties lye, hydrogen atoms were omitted for clarity. lengths and values of dihedral angles $(\Phi)$ at RT and LT while the details on intra- and intermolecular contacts are given in Table 2 and Table 3, respectively.

Compound 1 crystallizes in monoclinic system in the general position of $P 2_{1} / c$ space group with four molecules per unit cell. The molecular formula with the numbering scheme of $\mathbf{1}$ is given in Figure S4. As stated prior in text, the molecules of $\mathbf{1}$ are in enol-imine form both at RT and LT. The hydrogen atom $\mathrm{H} 1$ is located closer to the oxygen $\mathrm{O} 2$ atom then to the nitrogen atom $\mathrm{N} 1$ as can be seen in $\delta \mathrm{F}$ maps calculated through $\mathrm{N} 1-\mathrm{C} 7-\mathrm{C} 1-\mathrm{C} 2-\mathrm{O} 1$ chelate ring of $\mathbf{1}$ at RT and LT (Figure 4). The crystal of compound $\mathbf{1}$ changes its colour from red to yellow upon cooling (Figure 4). The values of $\mathrm{C2}-\mathrm{O} 1$ and $\mathrm{C} 7-\mathrm{N} 1$ are also in agreement with enol-imine form at both temperatures (Table 2).

The crystal of $\mathbf{2}$ changes its colour from red at RT to orange-yellow at LT (Figure 4). The molecules of $\mathbf{2}$ crystallize in orthorhombic system, in general position of $P 2{ }_{1} 2_{1} 2_{1}$ space group with four molecules per unit cell. The molecular formula with the numbering scheme of $\mathbf{2}$ is given in Figure S5. The H1-atom (at both temperatures) is located closer to the $\mathrm{N} 1$ than to the $\mathrm{O} 1$ atom in the intermolecular $\mathrm{H}$-bond (Figure 4). In this case the $01 \cdots \mathrm{N} 1$ distance is approximately $0.045 \AA$ shorter than in 1 (Table 2). The position of $\mathrm{H} 1$ indicates that the molecules of compound $\mathbf{2}$

Table 1. C7-N1 and C2-O1 bond lengths and dihedral angle $(\Phi)$ values in compounds $1-3$.

\begin{tabular}{ccccc}
\hline Compound & $d(\mathrm{C} 7-\mathrm{N} 1) / \AA$ & $d(\mathrm{C} 2-\mathrm{O} 1) / \AA$ & $\Phi /^{\circ}$ \\
\hline \multirow{2}{*}{1} & RT & $1.2740(17)$ & $1.3566(15)$ & $12.97(5)$ \\
& LT & $1.2808(16)$ & $1.3582(15)$ & $11.74(4)$ \\
2 & RT & $1.307(5)$ & $1.278(5)$ & $3.9(2)$ \\
& LT & $1.314(4)$ & $1.293(4)$ & $3.8(1)$ \\
3 & RT & $1.2954(18)$ & $1.3442(17)$ & $8.86(5)$ \\
\hline
\end{tabular}

Table 2. Intramolecular $\mathrm{O} 1 \cdots \mathrm{N} 1 \mathrm{H}$-bond parameters in compounds $1-3$ ( $D=$ donor atom, $A=$ acceptor atom).

\begin{tabular}{|c|c|c|c|c|}
\hline & $T / K$ & $D-H \cdots A$ & $d(D \cdots A) / \AA$ & $\Varangle(D-H \cdots A) /^{\circ}$ \\
\hline \multirow{2}{*}{1} & 298 & \multirow{2}{*}{$\mathrm{O} 1-\mathrm{H} 1 \cdots \mathrm{N} 1$} & $2.629(0)$ & $151(1)$ \\
\hline & 110 & & $2.625(2)$ & $152(2)$ \\
\hline \multirow{2}{*}{2} & 298 & \multirow{2}{*}{$\mathrm{N} 1-\mathrm{H} 1 \cdots \mathrm{O} 1$} & $2.576(0)$ & $138(1)$ \\
\hline & 110 & & $2.588(0)$ & $141(1)$ \\
\hline \multirow{4}{*}{3} & 298 & & \multirow[t]{2}{*}{$2.525(2)$} & $151(1)$ \\
\hline & & $\mathrm{O} 11-\mathrm{H} 11 \mathrm{a} \cdots \mathrm{N} 11$ & & $150(6)$ \\
\hline & & $\mathrm{N} 11-\mathrm{H} 11 \mathrm{~b} \cdots \mathrm{O} 11$ & & $151(5)$ \\
\hline & 110 & & $2.507(2)$ & $150(4)$ \\
\hline
\end{tabular}


are in keto-amine tautomeric form both at RT and LT while according to Figure 2 keto-enol tautomeric equilibrium would be expected Compound $\mathbf{2}$ shows reversible thermochromic properties (Figure 4) although a bit weaker than compound 1.

In the case of compound $\mathbf{3}$, two molecules per unit cell crystallize in $P \overline{1}$ space group of the triclinic system. The influence of the temperature change on the colour was not found in this case, however there is an influence on the tautomeric equilibrium (Figure 4). At RT about $60 \%$ of the molecules are in enol-imine form and $40 \%$ in keto-amine

Table 3. Intermolecular $\mathrm{H}$-bond parameters in compounds 1-3 ( $D$ = donor atom, $A$ = acceptor atom).

\begin{tabular}{|c|c|c|c|}
\hline$T / K$ & $D-H \cdots A$ & $d(D \cdots A) / \AA$ & $\Varangle(D-H \cdots A) /^{\circ}$ \\
\hline \multicolumn{4}{|c|}{ Compound 1} \\
\hline 298 & \multirow{2}{*}{$\mathrm{C} 4-\mathrm{H} 4 \cdots \mathrm{O} 3$} & $3.544(2)$ & $173.97(10)$ \\
\hline 110 & & $3.500(2)$ & 174.53(9) \\
\hline 298 & \multirow{2}{*}{$\mathrm{C} 14-\mathrm{H} 14 \mathrm{C} \cdots \mathrm{O} 3$} & $3.359(2)$ & $125.62(10)$ \\
\hline 110 & & $3.296(2)$ & 121.83(9) \\
\hline 298 & \multirow{2}{*}{$\mathrm{C} 14-\mathrm{H} 14 \mathrm{~b} \cdots \mathrm{O} 3$} & $3.509(2)$ & 157.72(10) \\
\hline 110 & & $3.460(2)$ & $161.26(8)$ \\
\hline 298 & \multirow{2}{*}{$\mathrm{C} 12-\mathrm{H} 12 \cdots \mathrm{O} 2$} & $3.502(2)$ & $145.79(9)$ \\
\hline 110 & & $3.428(1)$ & $145.28(8)$ \\
\hline \multicolumn{4}{|c|}{ Compound 2} \\
\hline 298 & \multirow{2}{*}{$\mathrm{O} 2-\mathrm{H} 2 \cdots \mathrm{O} 1$} & $2.619(5)$ & $164(5)$ \\
\hline 110 & & $2.627(4)$ & $160(4)$ \\
\hline 298 & \multirow{2}{*}{$\mathrm{C} 12-\mathrm{H} 12 \cdots \mathrm{O} 1$} & $3.559(6)$ & $121.24(34)$ \\
\hline 110 & & $3.514(5)$ & $122.06(23)$ \\
\hline 298 & \multirow{2}{*}{$\mathrm{C} 12-\mathrm{H} 12 \cdots \mathrm{O} 2$} & $3.330(7)$ & $105.24(34)$ \\
\hline 110 & & $3.320(5)$ & $101.57(23)$ \\
\hline 298 & \multirow{2}{*}{$\mathrm{C} 5-\mathrm{H} 5 \cdots \mathrm{O} 3$} & $3.484(6)$ & $152.37(32)$ \\
\hline 110 & & $3.441(5)$ & $150.34(23)$ \\
\hline \multicolumn{4}{|c|}{ Compound 3} \\
\hline 298 & \multirow{2}{*}{$\mathrm{O} 2-\mathrm{H} 2 \cdots \mathrm{O} 1$} & $2.683(2)$ & $176(2)$ \\
\hline 110 & & $2.650(2)$ & $176(2)$ \\
\hline 298 & \multirow{2}{*}{$\mathrm{C} 3-\mathrm{H} 3 \cdots \mathrm{O} 2$} & $3.459(2)$ & 126.50(9) \\
\hline 110 & & $3.399(2)$ & 126.67(9) \\
\hline 298 & \multirow{2}{*}{$\mathrm{C} 4-\mathrm{H} 4 \cdots \mathrm{O} 3$} & $3.466(2)$ & $125.71(9)$ \\
\hline 110 & & $3.424(2)$ & 124.33(9) \\
\hline 298 & \multirow{2}{*}{$\mathrm{C} 9-\mathrm{H} 9 \cdots \mathrm{O} 2$} & $3.479(1)$ & $145.46(7)$ \\
\hline 110 & & $3.412(1)$ & $144.76(7)$ \\
\hline 298 & \multirow{2}{*}{$\mathrm{C} 15-\mathrm{H} 15 \mathrm{~b} \cdots \mathrm{O} 2$} & $3.517(2)$ & $132.73(11)$ \\
\hline 110 & & $3.468(2)$ & $135.87(10)$ \\
\hline
\end{tabular}

form (Figure 1). By lowering down the temperature to $110 \mathrm{~K}$ the position of the tautomeric equilibrium changes and about $50 \%$ of the molecules are in enol-imine and $50 \%$ in keto-amine form. The split position of the H1-atom in the intramolecular $\mathrm{O} 1 \cdots \mathrm{N} 1$ hydrogen bond can be easily seen in Figure 4. The $\mathrm{C} 2-\mathrm{O} 1$ bond length at both temperatures is on the limiting value of the intermediary and the tabulated value (ESI, Table S7) for a pure enol-imine form (Figure 2). ${ }^{[25]}$ The N1-C7 bond length points to an equilibrium of both tautomers. The intramolecular $\mathrm{H}$-bond is even a bit shorter than in $\mathbf{1}$ and $\mathbf{2}$ (Table 3 ).

\section{Supramolecular Influences}

A detailed study of the differences in crystal packing of these three Schiff bases has led us to the opinion that the thermo-optical properties and keto-enol tautomerism are governed by supramolecular influences.
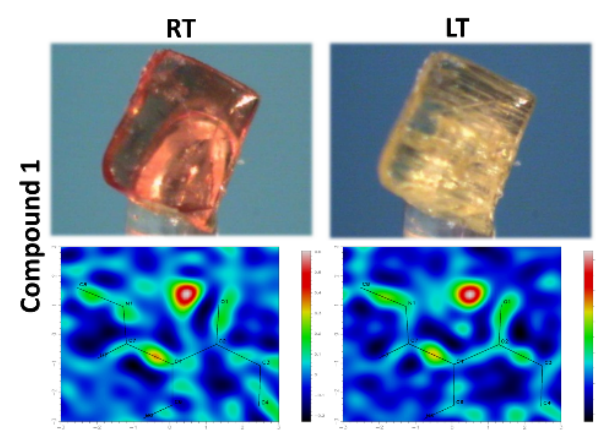

RT
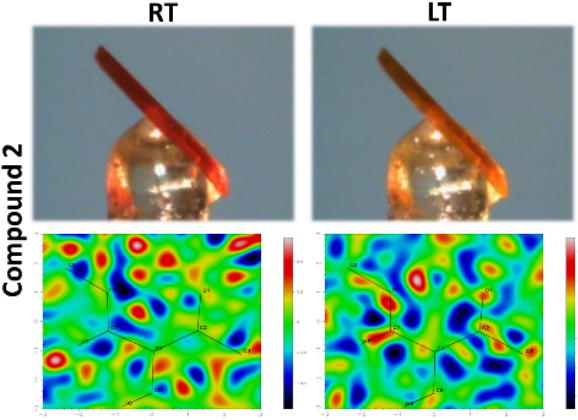

RT

LT

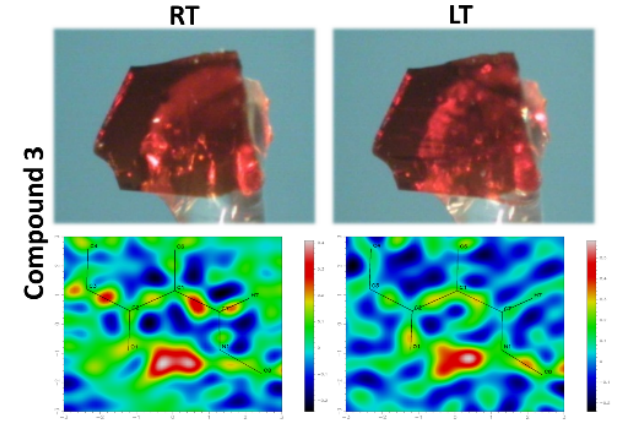

Figure 4. Photos of single crystals of compounds 1, 2 and 3 at $298 \mathrm{~K}$ and $110 \mathrm{~K}$. $\delta \mathrm{F}$ maps calculated through N1-C7-C1-C2-O1 chelate ring of 1, 2 and 3. 


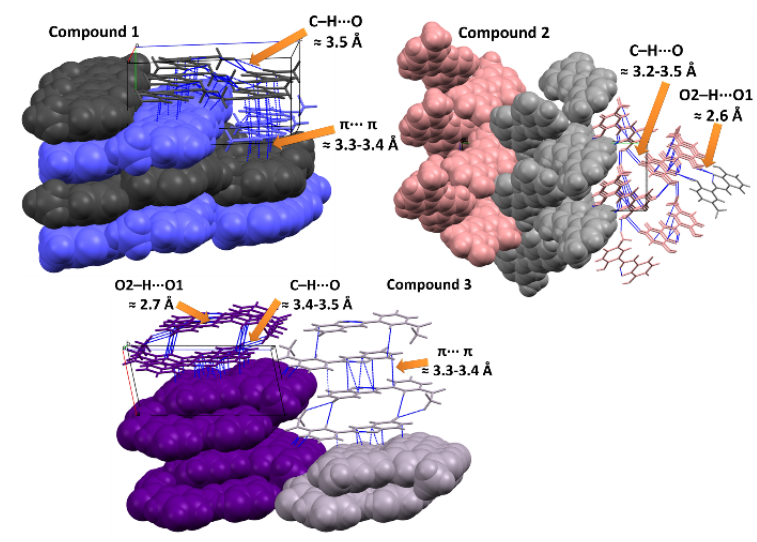

Figure 5. Packing diagrams of 1,2 and 3 . Interactions between molecules are highlighted.

The molecules are held together by three $\mathrm{C}-\mathrm{H} \cdots \mathrm{O} 3$ and one $\mathrm{C}-\mathrm{H} \cdots \mathrm{O} 2$ interaction of limiting values (Table 3 ) in dimers of 1D-chains formed via [100] direction. The $\pi \cdots \pi$ interactions via [010] direction are actually a bit shorter than the $\mathrm{C}-\mathrm{H} \cdots \mathrm{O}$ bonds and are governing the formation of 2D-sheets as can be seen in Figure 5 The 01 atom of molecules of compound $\mathbf{1}$ does not participate in any intermolecular bonding. the enol-imine form is favoured.

The molecules of $\mathbf{2}$ form 1D-chains via [001] direction by means of a strong $\mathrm{O} 2-\mathrm{H} 2 \cdots \mathrm{O} 1$ via [001] direction and 2D-sheets by means of three moderate $\mathrm{C}-\mathrm{H} \cdots \mathrm{O}$ (Table 3) interactions via [010]. These chains are further connected into 3D-sheets by $\pi \cdots \pi$ interactions (3.3-3.5 ̊̊) via [001] direction (Figure 5). In this case the 01 atom participates in a strong intermolecular bond mentioned above as a hydrogen bond acceptor. That led to "pushing" the $\mathrm{H} 1$-atom away from the parent oxygen $\mathrm{O} 1$ to

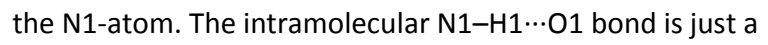
bit shorter (Table 2 ) than the intermolecular $\mathrm{O} 2-\mathrm{H} 2 \cdots \mathrm{O} 1$ interaction. Consequently, $\mathrm{O} 1$ atom is under supramolecular impact resulting in keto-amine tautomeric form.

In the case of compound $\mathbf{3}$ there is a tautomeric equilibrium The $\mathrm{O} 1$ atom participates in $\mathrm{O} 2-\mathrm{H} 2 \cdots \mathrm{O} 1$ interaction as well. However, here the $02 \cdots 01$ distance is a bit longer than in $\mathbf{2}$ (Table 3). This apparently facilitates the proton transfer from the parent oxygen $\mathrm{O} 1$ atom to the nitrogen $\mathrm{N} 1$ atom and vice versa and is crucial for the ketoenol tautomerism in this compound. The molecules of $\mathbf{3}$ form 1D-chains via [010] direction which are further connected into 3D-networks by means of four $\mathrm{C}-\mathrm{H} \cdots \mathrm{O}$ (Table 3 ) and by $\pi \cdots \pi$ interactions (3.3-3.4 $\AA$ ), Figure 5 .

In compound 3 , the supramolecular influence is greater than in $\mathbf{1}$ and milder than in $\mathbf{2}$ and consequently keto-enol tautomeric equilibrium can be observed. The described interactions in compounds $\mathbf{1 - 3}$ can be seen in 2D-fingerprint plots obtained from Hirshfeld surfaces ${ }^{[34]}$ (Figure 6).

\section{Thermal Study}

The thermal properties of the compounds were studied using DSC and TGA. This study, accompanied by PXRD experiments, revealed that compound 1 undergoes an endothermic polymorphic transition upon heating (Figure $\mathrm{S} 10, \mathrm{~S} 11)$ from form I reported here to form II. Compound 1 is stable up to $120^{\circ} \mathrm{C}$. From $121^{\circ} \mathrm{C}$ to $131^{\circ} \mathrm{C}$ it transforms to, for now, an unknown form,

form II, which crystallizes upon cooling to $25{ }^{\circ} \mathrm{C}$ (Figure 7). At temperatures above $132{ }^{\circ} \mathrm{C}$ the decomposition of 1 takes place at temperatures above $260{ }^{\circ} \mathrm{C}$. The DSC curve of compound $\mathbf{2}$ has an endothermic peak with an onset at $225^{\circ} \mathrm{C}$ which corresponds to melting of 2 . Starting at approx. $250{ }^{\circ} \mathrm{C}$ compound $\mathbf{2}$ decomposes exothermally (Figure S10, S12). Compound 3 starts to melt at $157^{\circ} \mathrm{C}$ and decomposes exothermally above $200^{\circ} \mathrm{C}$ (Figure S10, S13).

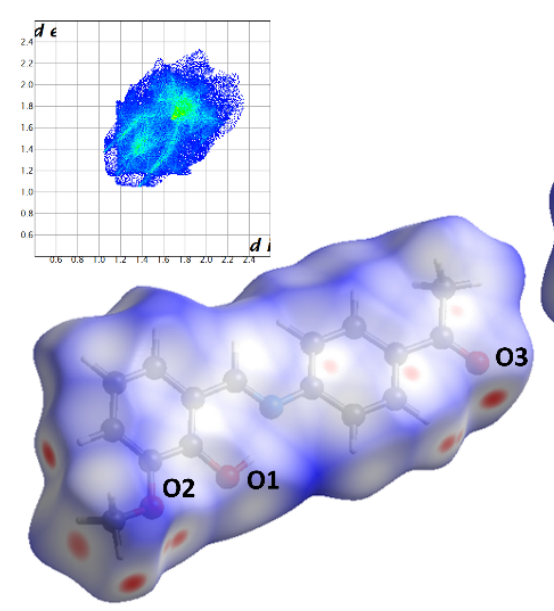

(a)

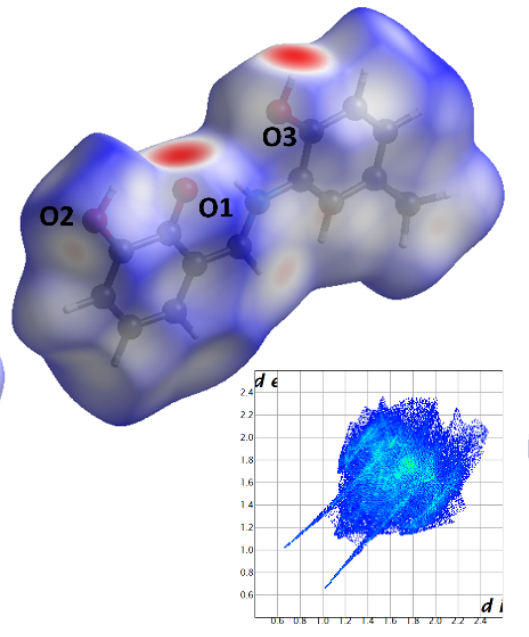

(b)

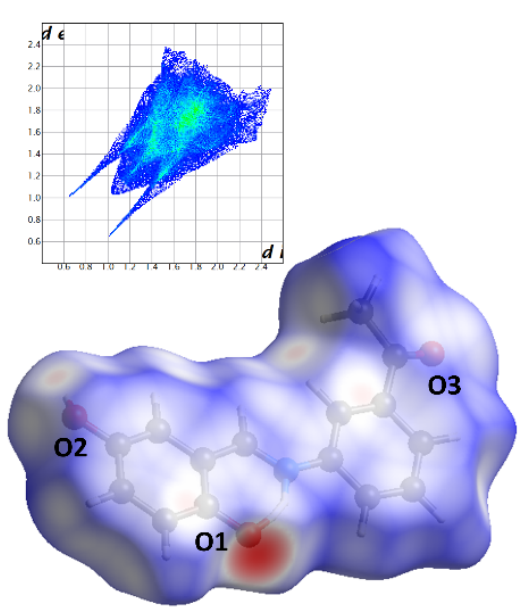

(c)

Figure 6. Hirshfeld surfaces and 2D-fingerprint plots of the molecules of (a) compound 1; (b) 2; and (c) 3. 


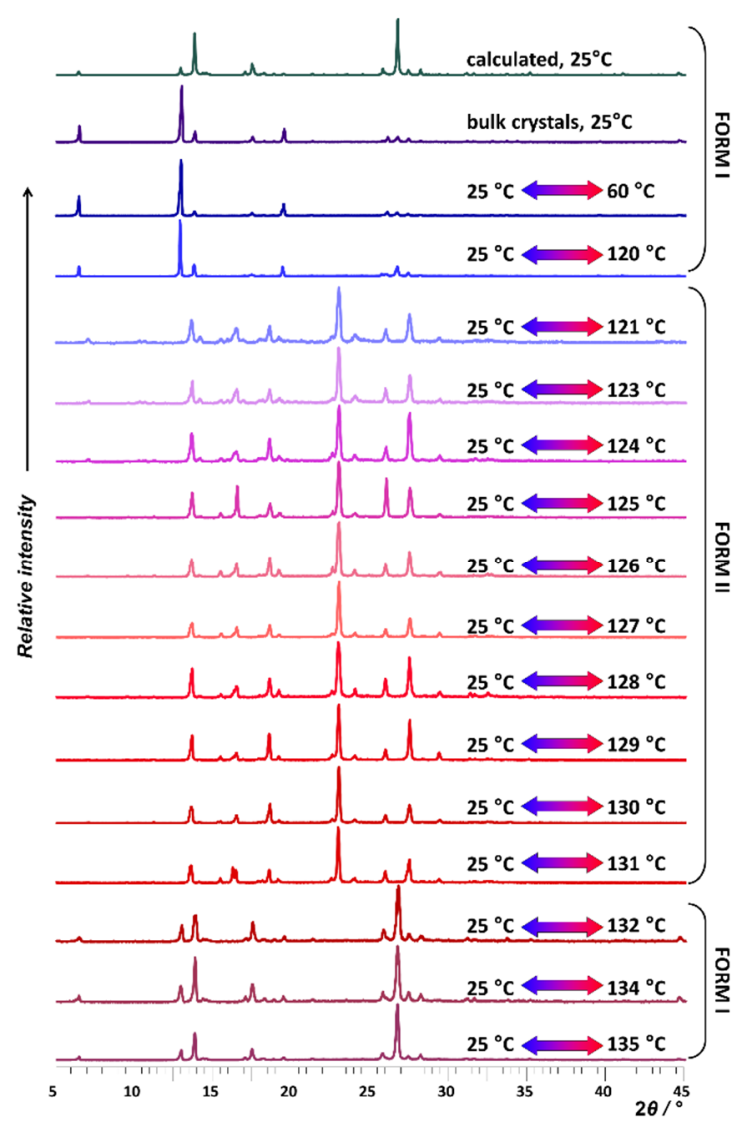

Figure 7. PXRD patterns of 1 heated up to a selected temperature and then cooled back to room temperature showing polymorphic transition at $121^{\circ} \mathrm{C}$ and $131^{\circ} \mathrm{C}$.

Intermolecular interaction strength vs. melting point as structure-property correlation has shown to be true in the case of the three compounds reported here. Table 4 comprises the values of melting points and the values of means of $d(\mathrm{D}-\mathrm{H} \cdots \mathrm{A})$. In the case of compounds $\mathbf{1}-\mathbf{3}$, the smaller the value of $\bar{d}$ the higher the melting onset meaning that the number and strength of the intermolecular interactions present directly impacts on the thermal stability i.e. melting of the material.

According to our experience and work on numerous examples of this kind of compounds this kind of structureproperty correlation should not be generalised.

Table 4. Values of $\bar{d}(\mathrm{D}-\mathrm{H} \cdots \mathrm{A})$ and melting onsets ( $\left.t_{\mathrm{e}}\right)$ in compounds 1-3 showing a good structure-property correlation.

\begin{tabular}{ccc}
\hline Compound & $d(D \cdots A) / \AA$ & $t_{\mathrm{e}} /{ }^{\circ} \mathrm{C}$ \\
\hline 1 & 3.479 & 121 \\
2 & 3.321 & 157 \\
3 & 3.248 & 225 \\
\hline
\end{tabular}

\section{CONCLUSION}

Herein, we report three o-hydroxy imines obtained by means of grinding. In the solid state, the molecules of compound $\mathbf{1}$ (ovan4aa) are in enol-imine tautomeric form, compound 2 (oOH2a4mp) was obtained as a keto-amine while there is a keto-enol tautomeric equilibrium in compound $\mathbf{3}$ (pOH3aa). The tautomerism of $\mathbf{1}$ and $\mathbf{2}$ is not influenced greatly by a temperature change although they do show thermochromic properties. On the other hand, there is a slight decrease in the population of molecules in enol-imine form with cooling but the colour change was not observed. We have demonstrated a huge effect of the type and strength of hydrogen bonds that involve the oxygen atom $\mathrm{O} 1$ on the keto-enol tautomerism. This has proved that the proton transfer via intramolecular $\mathrm{O} \cdots \mathrm{H} \cdots \mathrm{N}$ hydrogen bond is influenced strongly by supramolecular effects rather than by a change in molecular geometry in this type of compounds and that there is finally no doubt about the causes of keto-enol tautomerism in this class of compounds in the solid state.

The presented results are important for the understanding of supramolecular influences on macroscopic properties of imines, as well as on the possible design of other similar compounds that could be used as dyes or pigments. This study states out the importance of further research on this class of organic compounds in order to get better and detailed insight in solid-state and materials chemistry.

Acknowledgment. We acknowledge the financial support from the Ministry of Science and Technology of the Republic of Croatia (Grant No. 119-1193079-3069).

Supplementary Information. Supporting information to the paper is enclosed to the electronic version of the article at: http://dx.doi.org/10.5562/cca2881.

\section{REFERENCES}

[1] H. Schiff, Justus Liebigs Ann. Chim. 1864, 131, 118.

[2] S. L. James, C. J. Adams, C. Bolm, D. Braga, P. Collier, T. Friščić, F. Grepioni, K. D. M. Harris, G. Hyett, W. Jones, A. Krebs, J. Mack, L. Maini, A. Guy Orpen, I. P. Parkin, W. C. Shearouse, J. W. Steedk, D. C. Waddelli, Chem. Soc. Rev. 2012, 41, 413 and refences therein.

[3] J. Schmeyers, F. Toda, J. Boy, G. Kaupp, J. Chem. Soc. Perkin Trans. 1998, 2, 989.

[4] D. Cinčić, I. Brekalo, B. Kaitner, Chem. Commun. 2012, 48, 11683.

[5] K. Tanaka, F. Toda, Chem. Rev. 2000, 100, 1025.

[6] A. Carletta, J. Dubois, A. Tilborg, J. Wouters, CrystEngComm. 2015, 17, 3509. 
[7] M. Zbačnik, B. Kaitner, CrystEngComm. 2014, 16, 4162.

[8] B. Kaitner, M. Zbačnik, Acta Chim. Slov. 2012, 59, 670.

[9] M. Proetto, W. Liu, A. Hagenbach, U. Abram, R. Gust, Eur. J. Med. Chem. 2012, 53, 168.

[10] A. Blagus, D. Cinčić, T. Friščić, B. Kaitner, V. Stilinović, Maced. J. Chem. Chem. Eng. 2010, 29, 117.

[11] H. Bouas-Laurent, H. Durr, Pure Appl. Chem. 2001, 73, 639: Thermochromism is defined as a reversible colour change caused by a temperature change and photochromism is a reversible transformation of a chemical species induced in one or both directions by absorption of electromagnetic radiation between two forms having different absorption spectra.

[12] E. Hadjoudis, M. Vittorakis, I. M. Mavridis, Tetrahedron 1987, 43, 1345.

[13] E. Hadjoudis, I. M. Mavridis, Chem. Soc. Rev. 2004, 33, 579.

[14] M. D. Cohen, G. M. J. Schmidt, J. Phys. Chem. 1962, 66, 2442.

[15] M. D. Cohen, G. M. J. Schmidt, S. Flavian, J. Chem. Soc. 1964, 2030.

[16] M. D. Cohen, Y. Hirshberg, G. M. J. Schmidt, J. Chem. Soc. 1964, 2051.

[17] J. Bergman, L. Leiserowitz, G. M. J. Schmidt, J. Chem. Soc. 1964, 2060.

[18] J. Harada, T. Fujiwara, K. Ogawa, J. Am. Chem. Soc. 2007, 129, 16216.

[19] K. Ogawa, Y. Kasahara, Y. Ohtani, J. Harada, J. Am. Chem. Soc. 1998, 120, 7107.
[20] F. Robert, A. D. Naik, B. Tinant, R. Robiette, Y. Garcia, Chem. - Eur. J. 2009, 15, 4327.

[21] F. Robert, P.-L. Jacquemin, B. Tinant, Y. Garcia, CrystEngComm. 2012, 14, 4396.

[22] D. A. Safin, M. Bolte, Y. Garcia, CrystEngComm. 2014, 16, 87868793.

[23] M. Zbačnik, I. Nogalo, D. Cinčić, B. Kaitner, CrystEngComm. 2015, 17, 7870.

[24] F. H. Allen, Acta Crystallogr. B 2002, 58, 380.

[25] F. H. Allen, O. Kennard, D. G. Watson, L. A. Brammer, G. Orpen, J. Chem. Soc. Perkin Trans. 1987, 2, S1.

[26] I. J. Bruno, J. C. Cole, P. R. Edgington, M. Kessler, C. F. Macrae, P. McCabe, J. Pearson, R. Taylor, Acta Cryst. B 2002, 58, 389.

[27] C. F. Macrae, P. R. Edgington, P. McCabe, E. Pidcock, G. P. Shields, R. Taylor, M. Towler, J. van de Streek, J. Appl. Cryst. 2006, 39, 453.

[28] G. Rothenberg, A. P. Downie, C. L. Raston, J. L. Scott, J. Am. Chem. Soc. 2001, 123, 8701.

[29] O. Dolotko, J. W. Wiench, K. W. Dennis, V. K. Pecharsky, V. P. Balema, New J. Chem. 2010, 34, 25.

[30] G. Kaupp, CrystEngComm. 2003, 5, 117.

[31] R. Kuroda, K. Higashiguchi, S. Hasebe, Y. Imai, CrystEngComm. 2004, 6, 463.

[32] K. Chadwick, R. Davey, W. Cross, CrystEngComm. 2007, 9, 732.

[33] A. Jayasankar, A. Somwangthanaroj, Z. J. Shao, N. Rodríguez-Hornedo, Pharm. Res. 2006, 23, 2381.

[34] J. J. McKinnon, M. A. Spackman, A. S. Mitchell, Acta Crystallogr. Sect. B: Struct. Sci. 2004, 60, 627. 


\section{Supramolecular influence on keto-enol tautomerism and thermochromic properties of $o$-hydroxy Schiff bases}

\section{Marija Zbačnik* and Branko Kaitner}

a Laboratory of General and Inorganic Chemistry, Department of Chemistry, Faculty of Science, University of Zagreb, Horvatovac 102a, HR-10002 Zagreb, Croatia

Email: mzbacnik@chem.pmf.hr

Fax: +38514606341

Tel: +38514606379

\section{Table of Contents}

1. EXPERIMENTAL DETAILS $\quad 2$

1.1. Materials 2

1.2. Mechanochemical synthesis accompanied by PXRD experiments 2

1.2.1. Synthesis of compound $\mathbf{1} \quad 2$

1.2.2. Synthesis of compound $2 \quad 3$

1.2.3. Synthesis of compound $3 \quad 3$

1.3. Powder X-Ray Diffraction experiments - PXRD 4

1.4. Single Crystal X-Ray Diffraction experiments - SCXRD 4

$\begin{array}{lr}\text { 1.5. Thermal Study } & 4\end{array}$

$\begin{array}{lll}\text { 1.5.1. } & \text { DSC experiments } & 4\end{array}$

$\begin{array}{ll}\text { 1.5.2. TG experiments } & 5\end{array}$

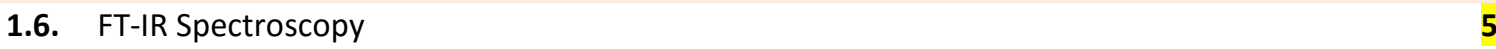

$\begin{array}{lr}\text { 2. } & \text { RESULTS } \\ \end{array}$

2.1. Results of SCXRD $\quad 6$

2.2. Thermal ellipsoid plots with crystallographic labelling scheme 9

$\begin{array}{lr}\text { 2.3. } \delta \mathrm{F} \text { maps } & 12\end{array}$

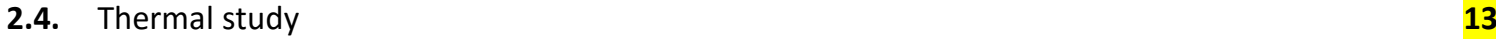

\begin{tabular}{lr} 
2.5. & Results of FT-IR spectroscopic measurements \\
\hline
\end{tabular}

$\begin{array}{lrr}\text { 2.6. } & \text { Results of the CSD search } & 17\end{array}$

2.7. Values of single and double bonds according to tabular values used often for tautomer selection $\quad 19$

\begin{tabular}{lr}
3. & REFERENCES \\
\hline
\end{tabular} 


\subsection{Materials}

All reagents and solvents were purchased from commercial sources and used as received. Table S2 comprises all starting materials and solvents used for syntheses, crystallization or liquidassisted grinding experiments.

Table S1 Starting materials used for various experiments.

\begin{tabular}{|c|c|c|}
\hline Name & Acronym & Manufacturer \\
\hline Ortho-vanillin & ovan & Acros Organics \\
\hline Ortho-hydroxysalicylaldehyde & oOH & Aldrich \\
\hline Para-hydroxysalicylaldehyde & pOH & Aldrich \\
\hline 3-aminoacetophenone & 3aa & Merck \\
\hline 4-aminoacetophenone & 4aa & Merck \\
\hline Acetonitrile & MeCN & J.T.Baker \\
\hline Tetrahydrofuran & thf & Kemika \\
\hline
\end{tabular}

\subsection{Mechanochemical synthesis accompanied by PXRD experiments}

All grinding experiments were performed in an agate mortar at RT and $40-50 \%$ relative humidity. The required grinding time in the agate mortar was determined empirically when the colour of the reaction mixture stopped changing. PXRD experiments were performed on all powder products obtained by grinding to check if the condensation reaction of the aldehyde and amine yielded in product.

\subsubsection{Synthesis of compound 1}

Equimolar quantities of ovan $(0.153 \mathrm{~g}, 1 \mathrm{mmol})$ and 4 aa $(0.135 \mathrm{~g}, 1 \mathrm{mmol})$ were first ground in an agate mortar at $25^{\circ} \mathrm{C}$. After $40 \mathrm{~s}$ an orange paste appears which solidifies in an orange powder after 3 minutes (Figure S1 A)). The PXRD data of that material revealed some traces of unreacted material so the reaction was repeated but by means of LAG in presence of $20 \mu \mathrm{L}$ of MeCN added in the reaction mixture. Orange powder of compound $\mathbf{1}$ (ovan4aa) was obtained again and the PXRD data of the powder product is in good agreement with the calculated pattern. Small amount of the obtained powder was dissolved in acn and the single crystals suitable for SCXRD experiments were obtained by slow evaporation of solvent. 


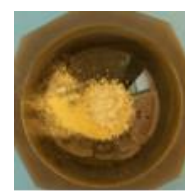

$0 \mathrm{~s}$

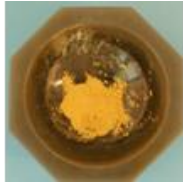

$10 \mathrm{~s}$

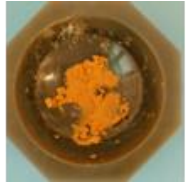

$40 \mathrm{~s}$

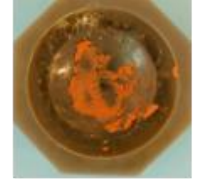

$50 \mathrm{~s}$

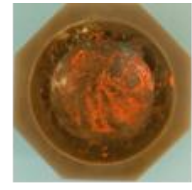

$1 \mathrm{~min}$

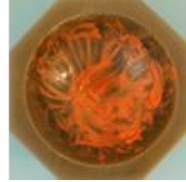

$1.5 \mathrm{~min}$

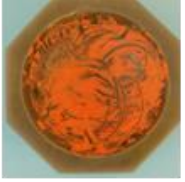

$2 \min$

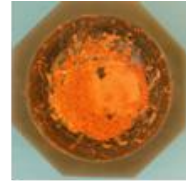

$3 \mathrm{~min}$

Figure S1 Neat grinding of ovan and 4aa in an agate mortar.

\subsubsection{Synthesis of compound 2}

Compound 2, $\mathrm{OOH2a4mp}$, was obtained by NG of equimolar quantities of $\mathrm{OOH}(0.135 \mathrm{~g}, 1 \mathrm{mmol})$ and $2 \mathrm{a} 4 \mathrm{mp}(0.123 \mathrm{~g}, 1 \mathrm{mmol})$ in an agate mortar at $25^{\circ} \mathrm{C}$ for 11 minutes and the reaction mixture did not change its colour. For that reason, $20 \mu \mathrm{L}$ of thf was added in the reaction mixture and the mixture started changing its colour from yellow to orange. Finally, an orange powder of compound $\mathbf{2}$ was obtained in 14 minutes of grinding in total. The PXRD data of the powder product obtained by LAG is in a good agreement with the calculated pattern. Small amount of the obtained powder was dissolved in thf and the single crystals suitable for SCXRD experiments were obtained by slow evaporation of solvent.

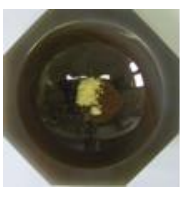

$0 \mathrm{~s}$

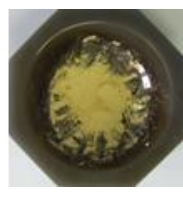

$10 s$

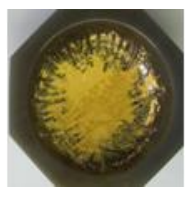

$1 \mathrm{~min}$

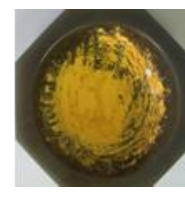

$10 \mathrm{~min}$

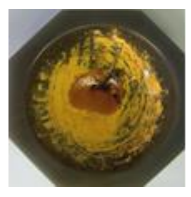

$11 \mathrm{~min}$

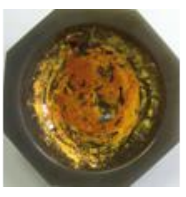

$12 \mathrm{~min}$

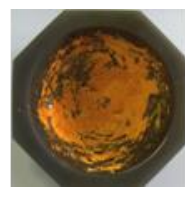

$13 \mathrm{~min}$

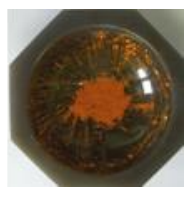

$14 \mathrm{~min}$

Figure S2 Liquid-assisted grinding of $\mathbf{O O H}$ and $2 \mathrm{a} 4 \mathrm{mp}$ in an agate mortar.

\subsubsection{Synthesis of compound 3}

Red powder of compound 3, pOH3aa, was obtained as by NG of equimolar quantities of pOH $(0.135 \mathrm{~g}$, $1 \mathrm{mmol})$ and 3aa $(0.135 \mathrm{~g}, 1 \mathrm{mmol})$ in an agate mortar at $25^{\circ} \mathrm{C}$. After about 10 minutes of grinding a red paste starts to appear and it starts to solidify in about 2 minutes. The PXRD data of the red powder product is in good agreement with the calculated pattern. Small amount of the obtained powder was dissolved in MeCN and the single crystals suitable for SCXRD experiments were obtained by slow evaporation of solvent.

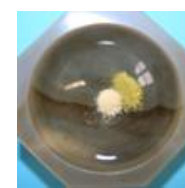

$0 \mathrm{~s}$

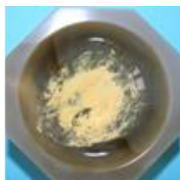

$10 \mathrm{~s}$

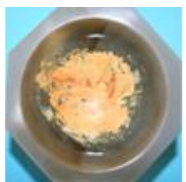

$1 \mathrm{~min}$

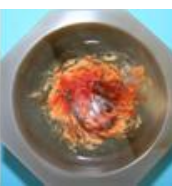

$10 \mathrm{~min}$

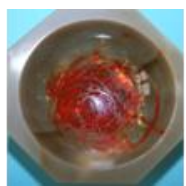

$11 \mathrm{~min}$

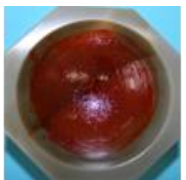

$12 \mathrm{~min}$

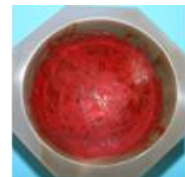

$13 \mathrm{~min}$

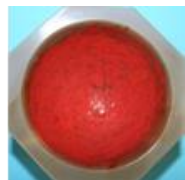

$14 \mathrm{~min}$

Figure S3 Neat grinding of $\mathbf{p O H}$ and 3aa in an agate mortar. 


\subsection{Powder X-Ray diffraction experiments}

Powder X-ray diffraction (PXRD) experiments were performed on a PHILIPS PW 1840 X-ray diffractometer with CuK $K_{\alpha 1}(1.54056 \AA)$ radiation at $40 \mathrm{~mA}$ and $40 \mathrm{kV}$. The scattered intensities were measured with a scintillation counter. The angular range $(2 \theta)$ was from 5 to $45^{\circ}$ with steps of $0.02^{\circ}$, and the measuring time was $0.5 \mathrm{~s}$ per step. The data collection and analysis were performed using the program package Philips $X^{\prime}$ Pert. ${ }^{[1,2,3]}$

\subsection{Single Crystal $X$-Ray diffraction experiments}

Crystal and molecular structures were determined at 298 and $110 \mathrm{~K}$ using single crystal X-ray diffraction. Diffraction measurements were made on an Oxford Diffraction Xcalibur Kappa CCD X-ray diffractometer with graphite-monochromated $\operatorname{MoK}_{\alpha}(\lambda=0.71073 \AA)$ radiation and the instrument was operated using CrysAlis $C C D$ and RED. ${ }^{[4]}$ The data sets were collected using the $\omega$ scan mode over the $2 \theta$ range up to $54^{\circ}$. The structures were solved by direct methods and refined using the SHELXS and SHELXL programs, respectively. ${ }^{[5]}$ The structural refinement was performed on $F^{2}$ using all data. The hydrogen atoms not involved in hydrogen bonding were placed in calculated positions and treated as riding on their parent atoms $[\mathrm{C}-\mathrm{H}=0.93 \AA$ and $U_{\text {iso }}(H)=1.2 U_{\text {eq }}(C) ; C-H=0.97 \AA$ and $U_{\text {iso }}(H)=1.2 U_{\text {eq }}(C)$ ] while the others were located from the electron difference map. All calculations were performed using the WinGX crystallographic suite of programs. ${ }^{[6]}$ The data concerning the results of the crystallographic experiments are listed in Table S2. Further details are available from the Cambridge Crystallographic Centre $(1442712-1442714) .{ }^{[7]}$ Molecular structures of compounds are presented using ORTEP-3 ${ }^{[8]}$ and are presented in Figures S4-S6 and their packing diagrams were prepared using Mercury. ${ }^{\left[{ }^{[9}\right.}$

\subsection{Thermal study}

\subsubsection{DSC experiments}

The measurements were performed on a Mettler Toledo $\mathrm{DSC} 823^{\mathrm{e}}$ module in sealed aluminium pans $(40 \mu \mathrm{L})$, heated in flowing nitrogen $\left(200 \mathrm{~mL} \mathrm{~min}^{-1}\right)$ at a rate of $10{ }^{\circ} \mathrm{Cmin}^{-1}$. The data collection and analysis was performed using the program package STAR ${ }^{\mathrm{e}}$ Software 9.01. $\left[{ }^{10}\right]$.

Samples of compound 1 , were heated to fifteen different temperatures $\left(60{ }^{\circ} \mathrm{C}, 120-135^{\circ} \mathrm{C}\right)$ and then kept at those selected temperatures for 5 minutes as well. After that, the samples were cooled to $25^{\circ} \mathrm{C}$ 
and PXRD measurements on the obtained material were done revealing that form I of compound 1 undergoes a temperature induced transformation at temperatures between 121 and $131^{\circ} \mathrm{C}$.

\subsubsection{TG experiments}

The measurements were performed on a Mettler Toledo TGA/SDTA 851 module in sealed aluminium pans $(40 \mu \mathrm{L})$, heated in flowing nitrogen $\left(200 \mathrm{~mL} \mathrm{~min}{ }^{-1}\right)$ at a rate of $10^{\circ} \mathrm{C} \mathrm{min}^{-1}$. The data collection and analysis was performed using the program package STAR Software 9.01. $\left[{ }^{11}\right]$.

\subsection{FT-IR spectroscopy}

Infrared spectra were recorded on a PerkinElmer Spectrum Two FTIR spectrophotometer using the $\mathrm{KBr}$ pellet method. The data collection and analysis was performed using the program package PerkinElmer Spectrum 10.4.2.279[12] Table S5 comprises data for the characteristic stretching bands for 1, 2 and 3 . 


\section{RESULTS \\ 2.1. Results of SCXRD}

Table S2 General and crystallographic data for 1 at 298 and $110 \mathrm{~K}$.

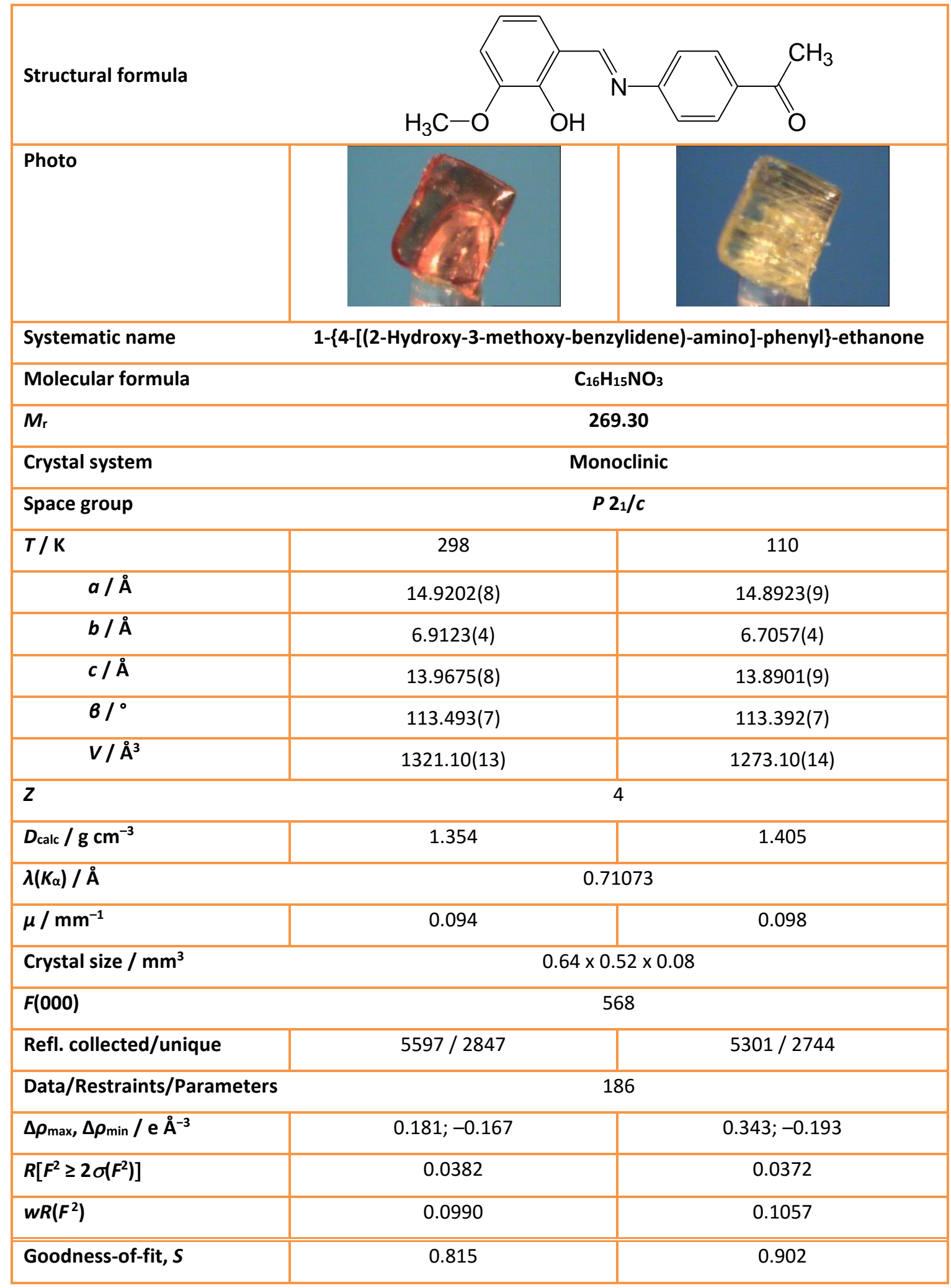


Table S3. General and crystallographic data for 2 at 298 and $110 \mathrm{~K}$.

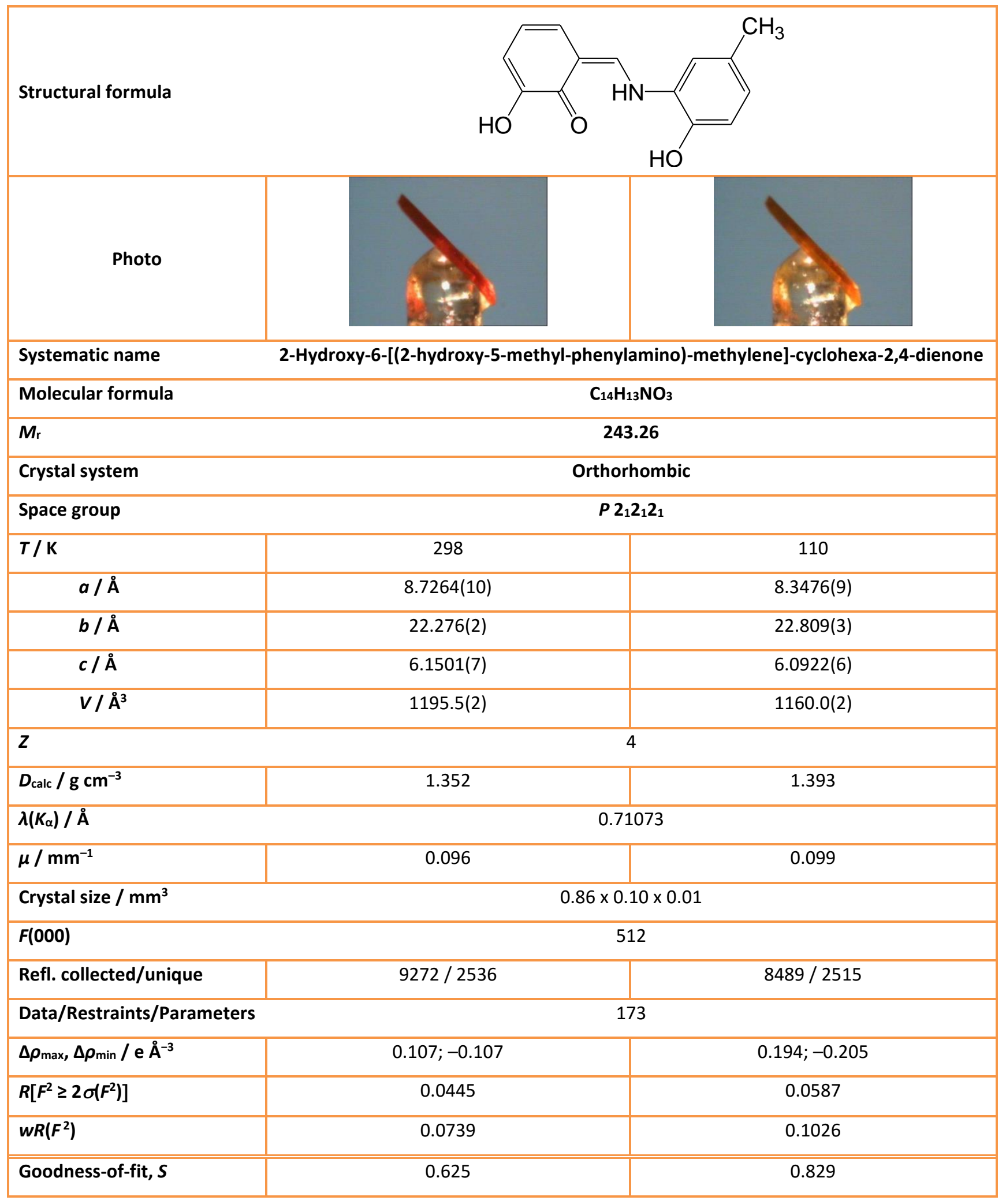


Table S4. General and crystallographic data for 2 at 298 and $110 \mathrm{~K}$.

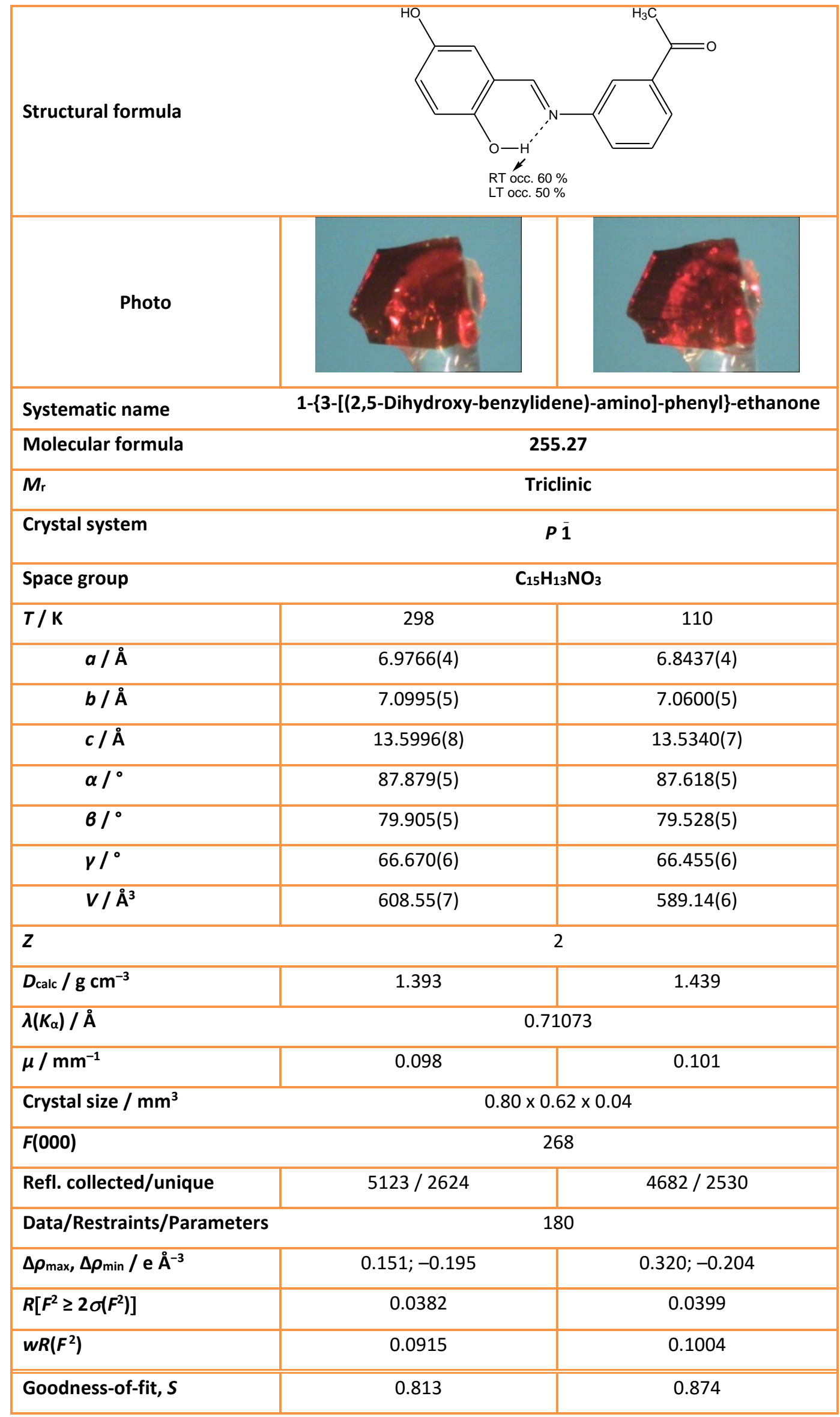




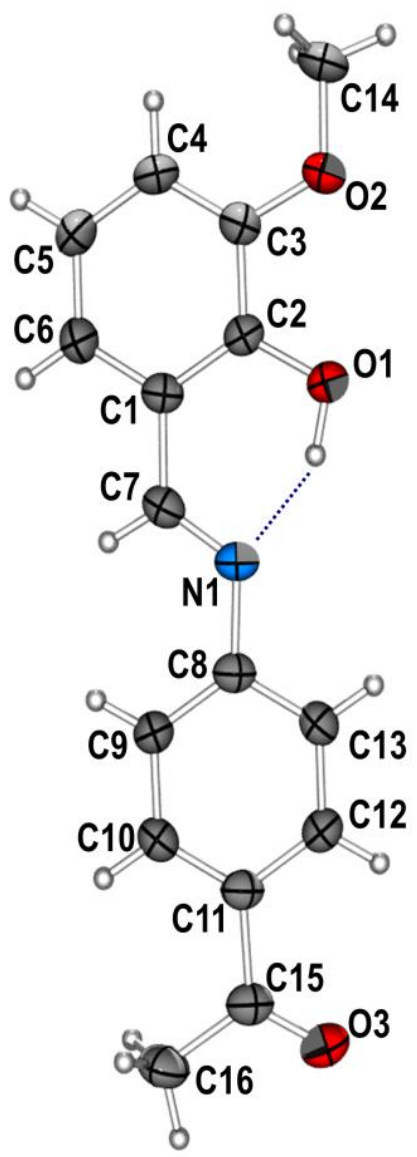

RT

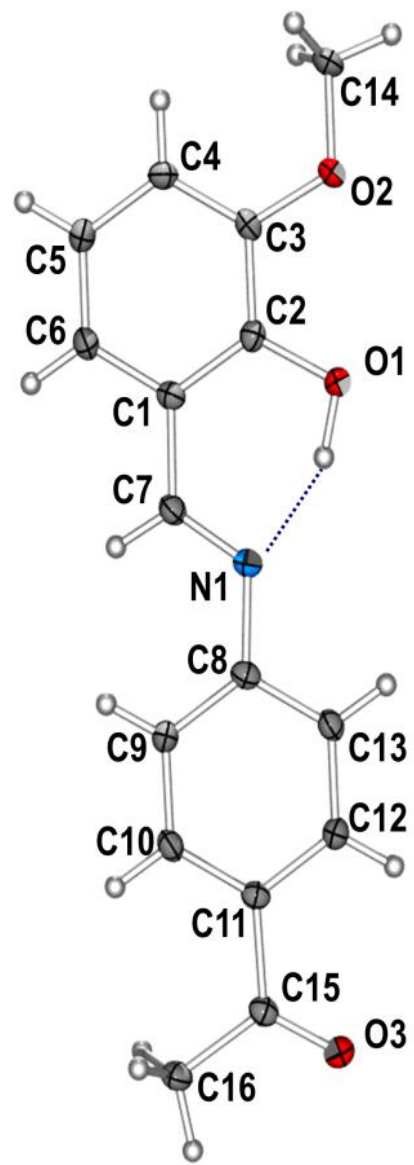

LT

Figure S4 Thermal ellipsoid (50\%) plot of compound 1 molecule with the atom-labelling scheme. Dashed line indicates intramolecular interaction. 

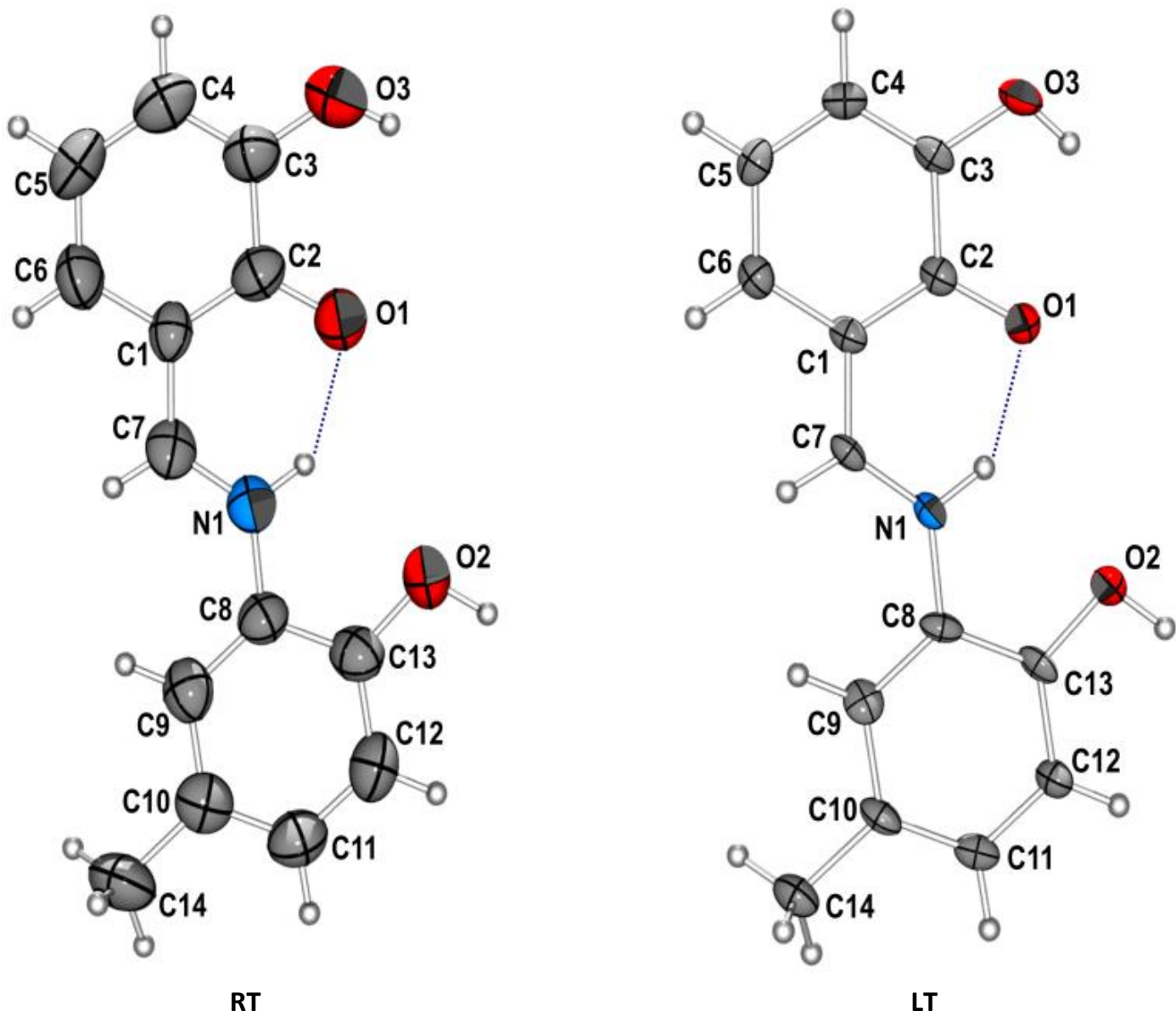

Figure S5 Thermal ellipsoid (50\%) plot of compound $\mathbf{2}$ molecule showing the atom-labelling scheme. Dashed line indicates intramolecular interaction. 


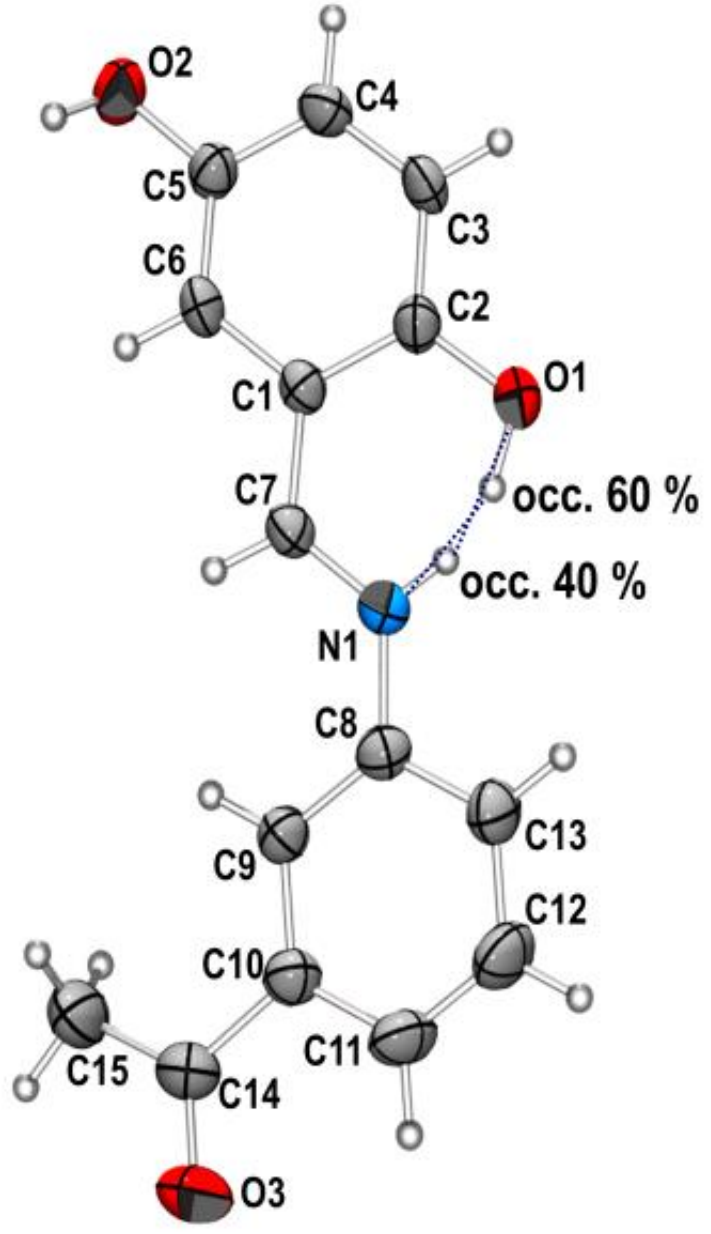

RT

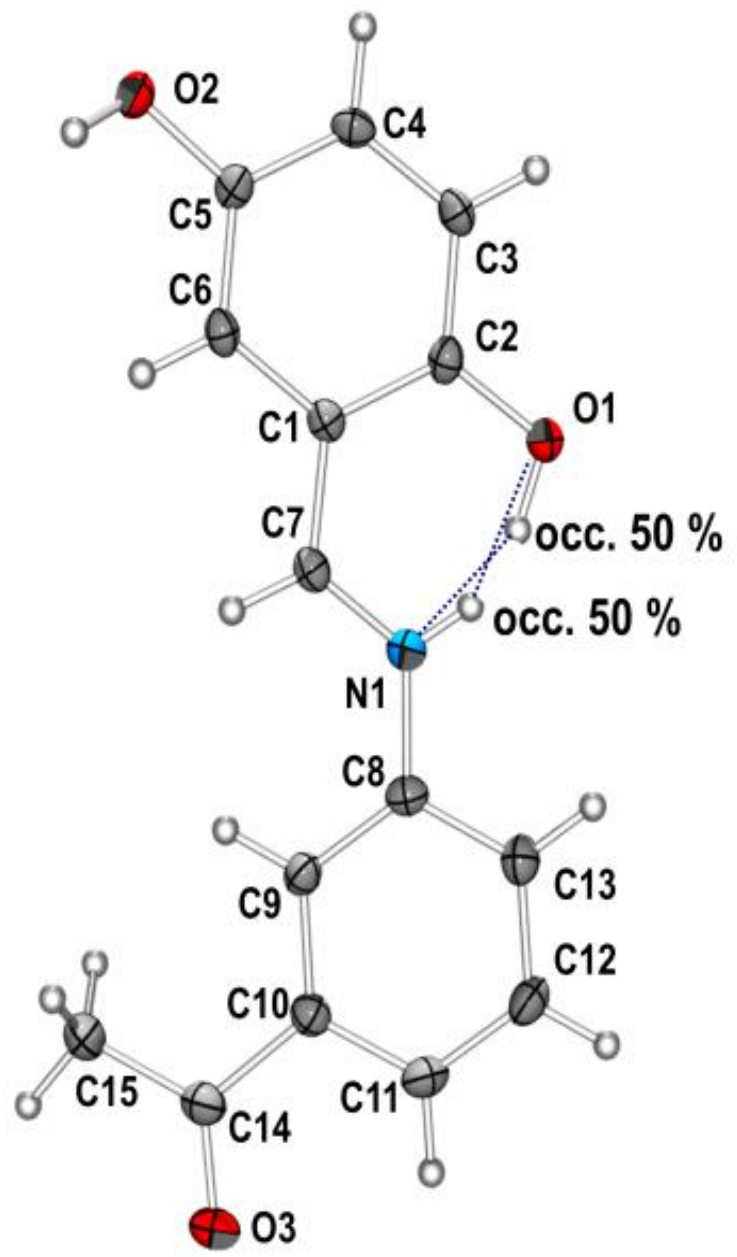

LT

Figure $\mathbf{S 6}$ Thermal ellipsoid ( $50 \%$ ) plot of compound $\mathbf{3}$ molecule showing the atom-labelling scheme and indicating the occupancy of the hydrogen atom. Dashed line indicates intramolecular interactions. 

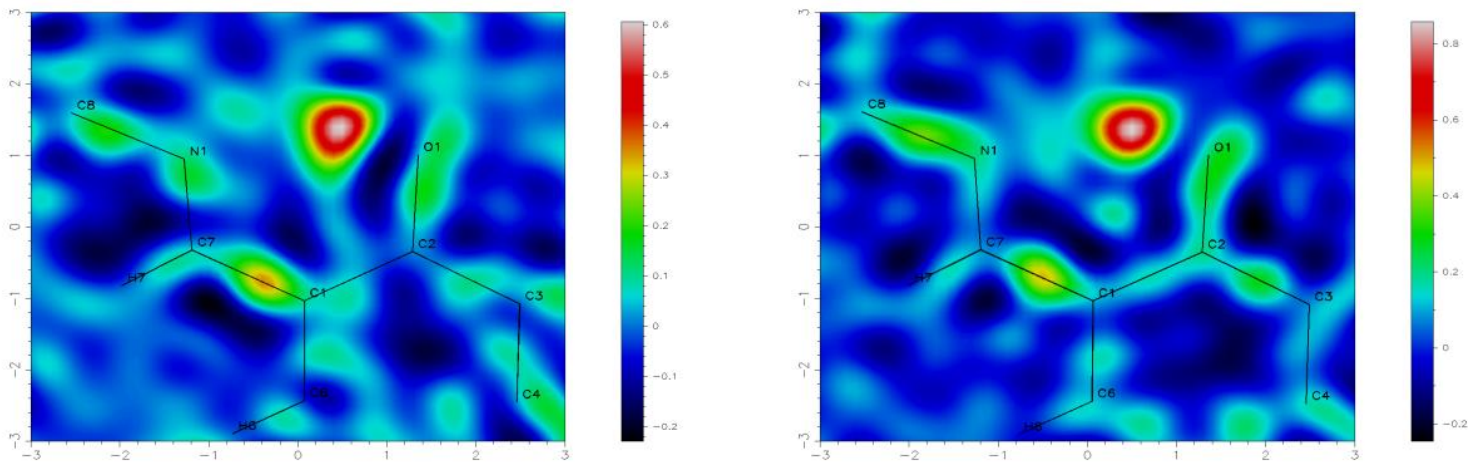

RT

LT

Figure S7 $\delta$ F maps calculated through N1-C7-C1-C2-O1 chelate ring of 1 at RT and LT.

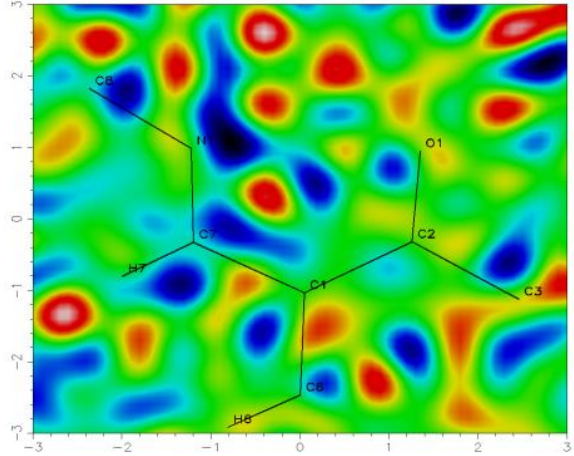

RT

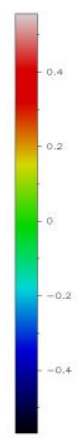

LT

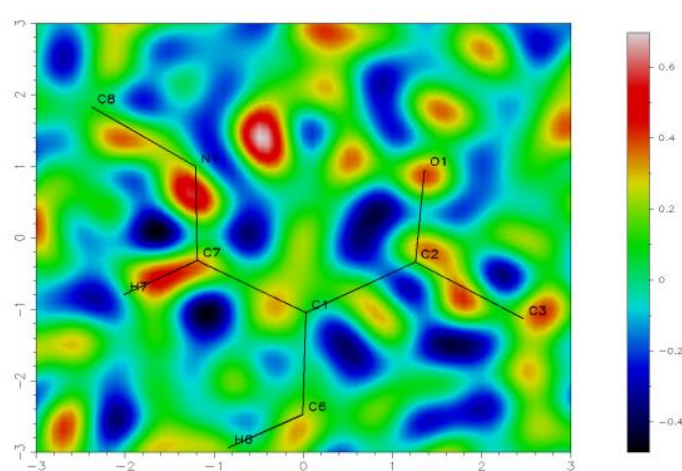

Figure $\mathbf{S} 8 \delta \mathrm{F}$ maps calculated through $\mathrm{N} 1-\mathrm{C} 7-\mathrm{C} 1-\mathrm{C} 2-\mathrm{O} 1$ chelate ring of $\mathbf{2}$ at RT and LT.

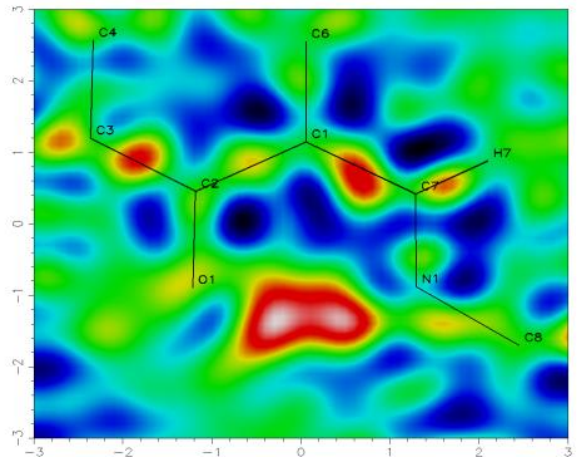

RT

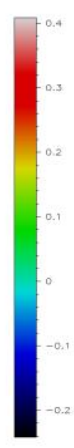

西

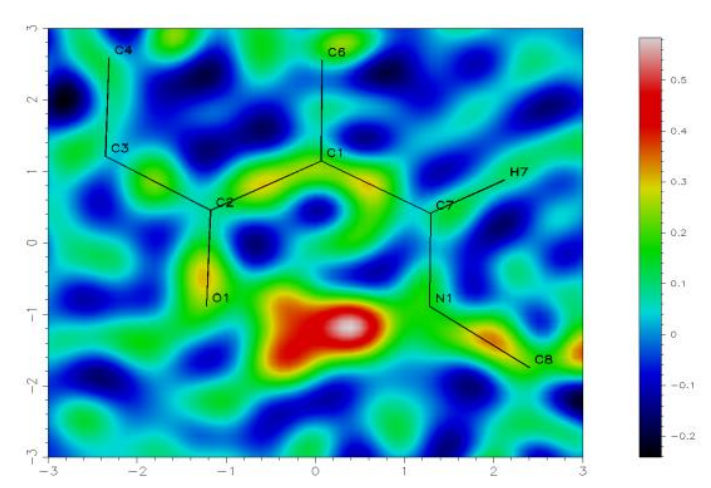

LT

Figure S9 $\delta \mathrm{F}$ maps calculated through $\mathrm{N} 1-\mathrm{C} 7-\mathrm{C} 1-\mathrm{C} 2-\mathrm{O} 1$ chelate ring of $\mathbf{3}$ at RT and LT. 


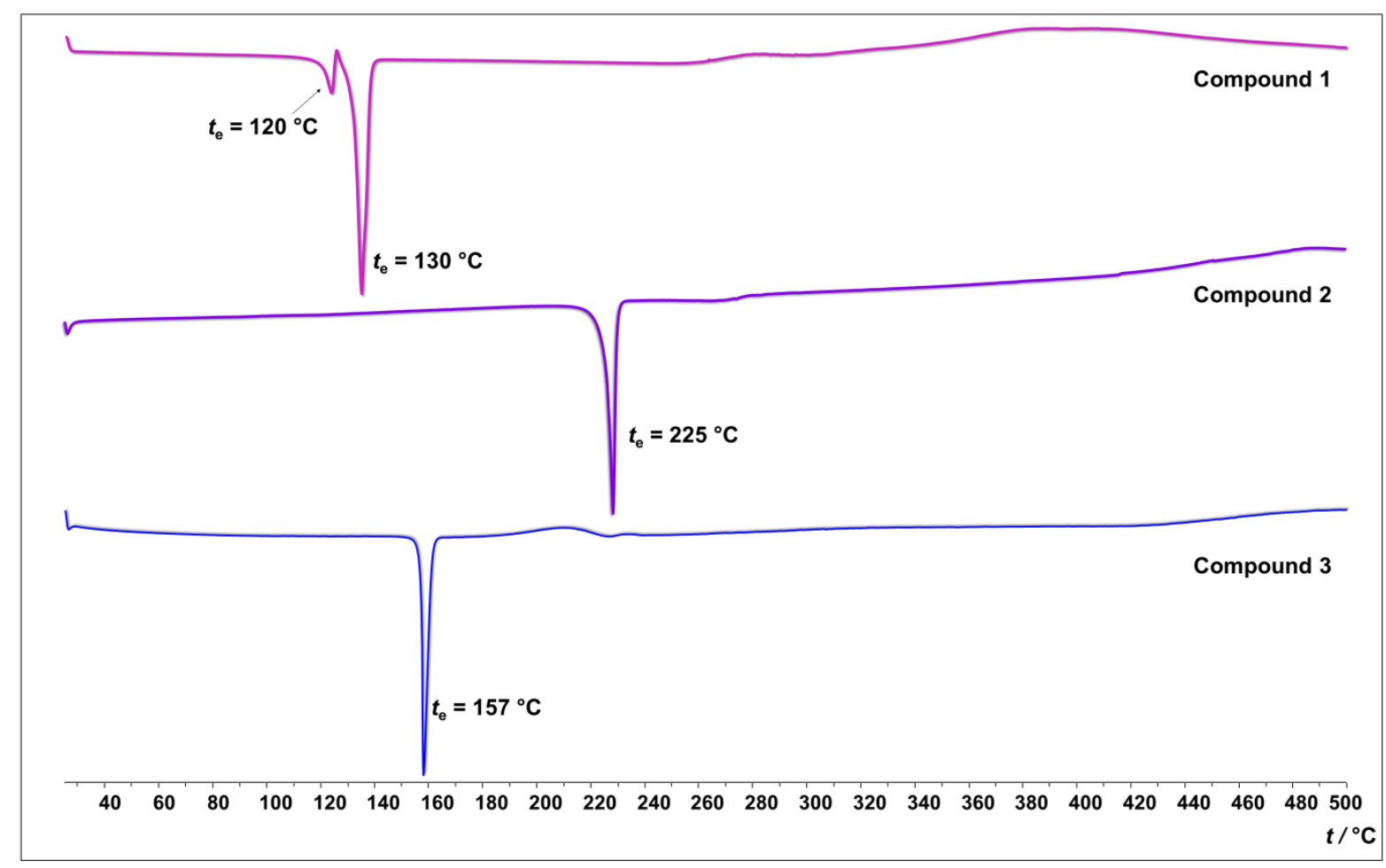

Figure S10 DSC curves of recrystallized material of compound $\mathbf{1}$ (pink), $\mathbf{2}$ (purple) and $\mathbf{3}$ (blue).

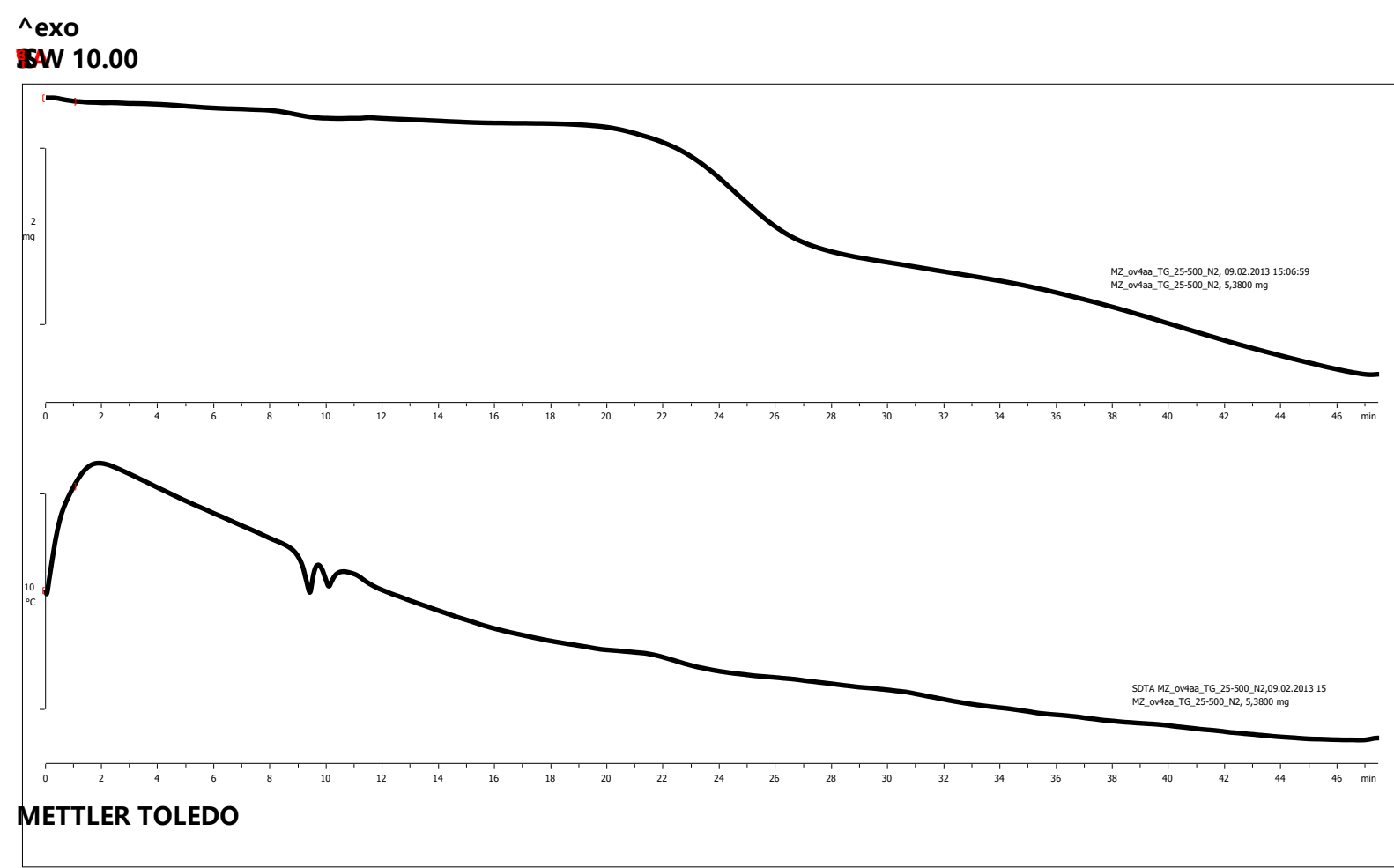

Figure S11 TGA and SDTA curves of recrystallized material of compound $\mathbf{1 .}$ 


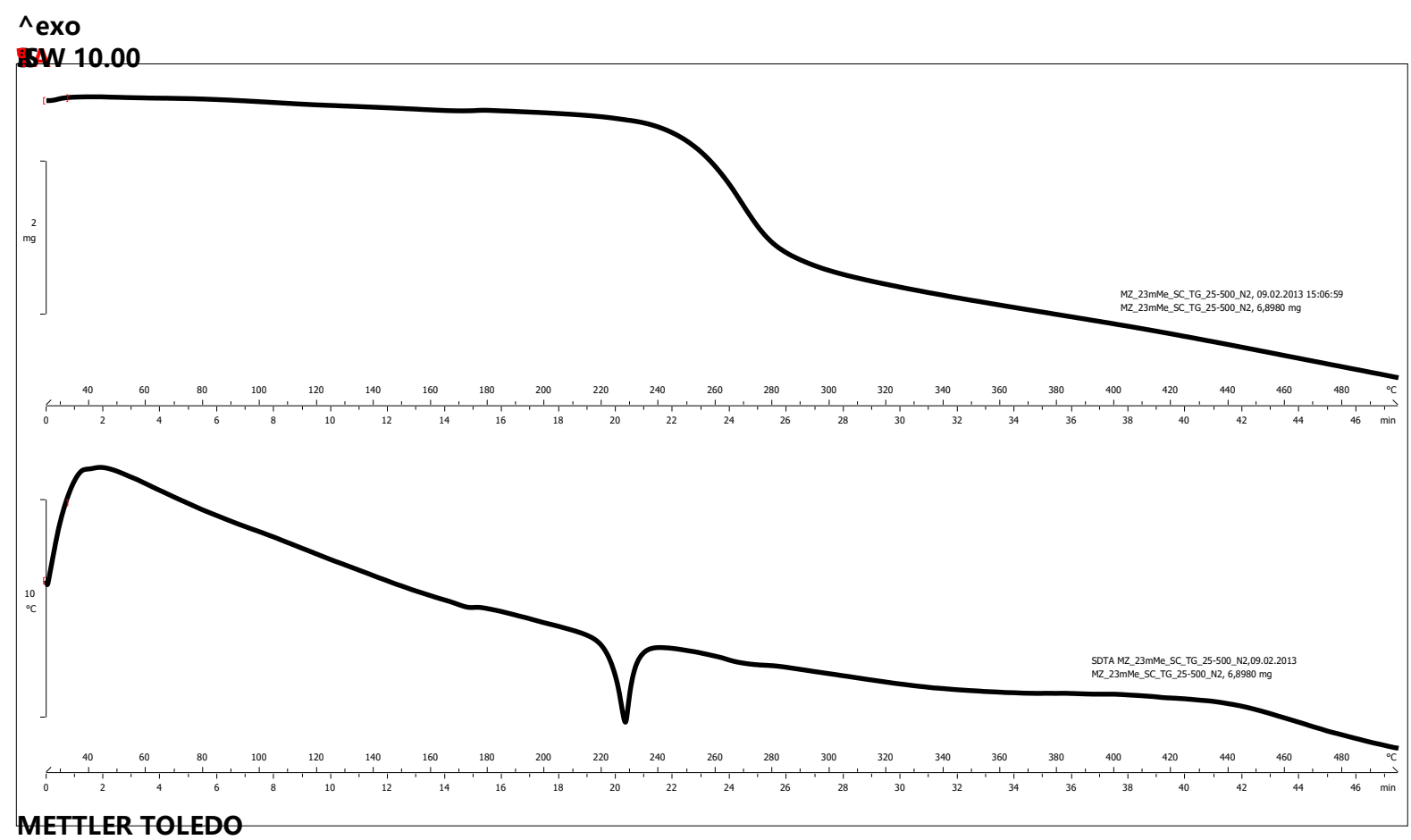

Figure S12 TGA and SDTA curves of recrystallized material of compound 2.

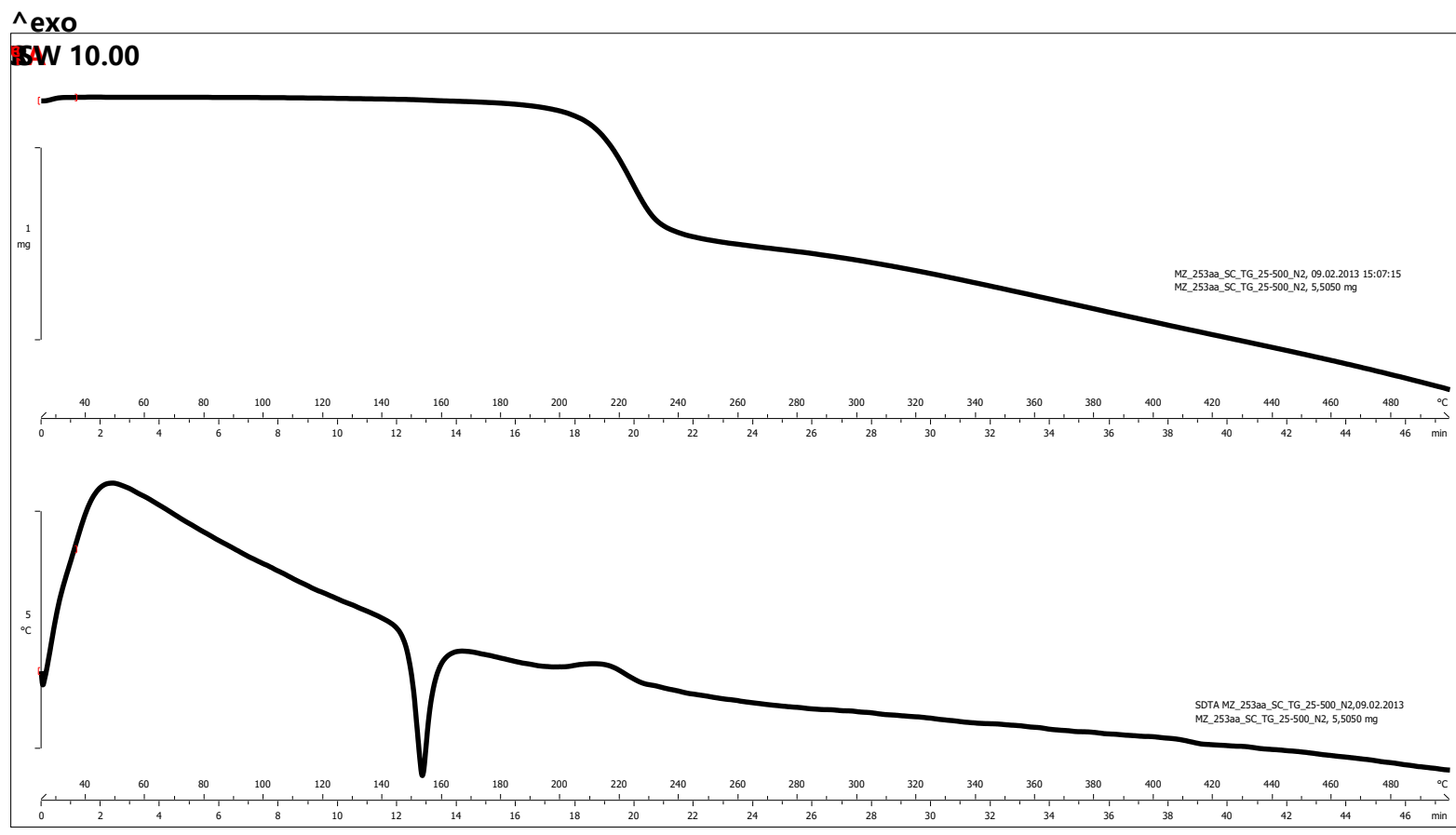

METTLER TOLEDO

Figure S13 TGA and SDTA curves of recrystallized material of compound 3. 


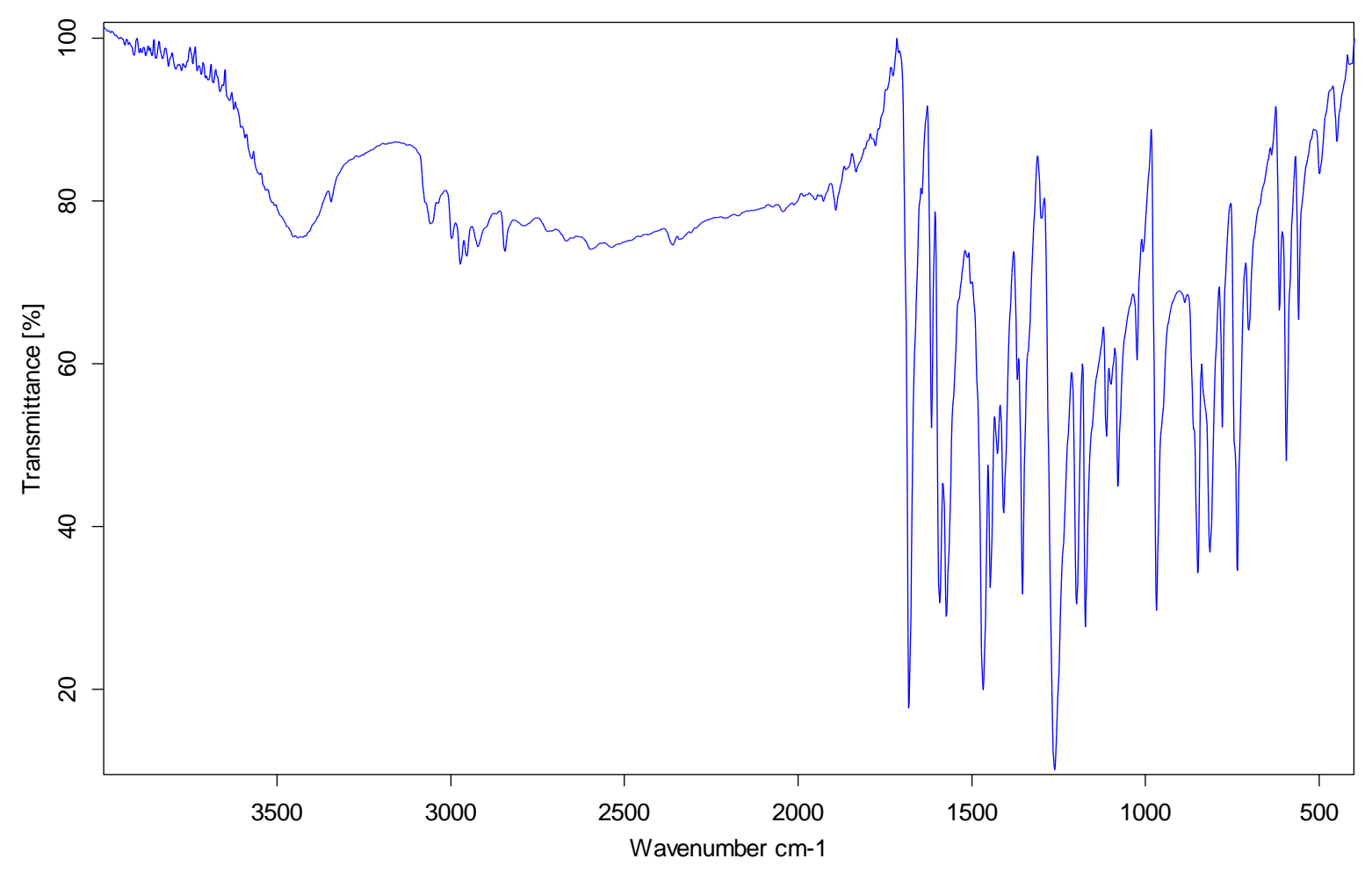

Figure S14 IR spectrum of compound 1.

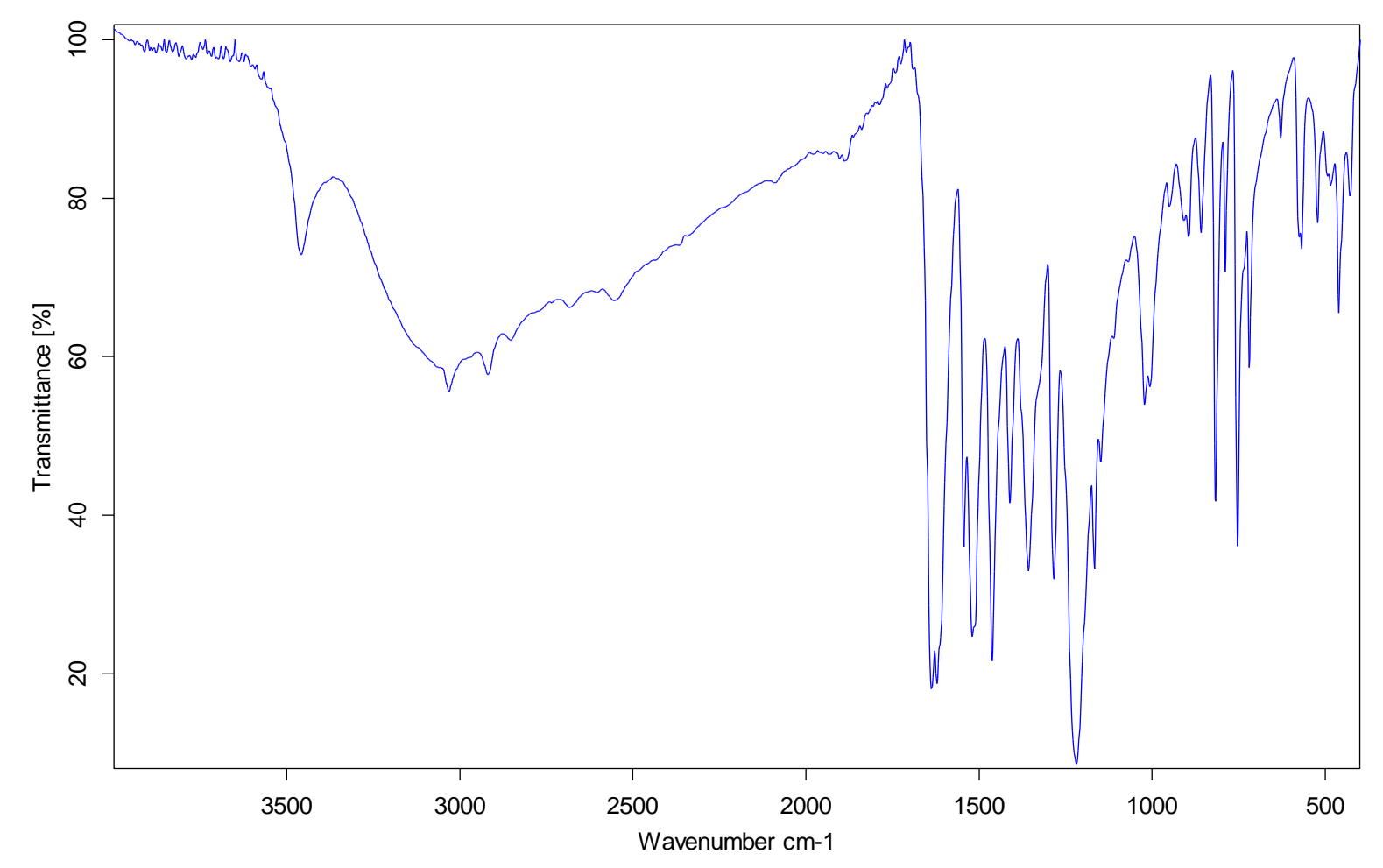


Figure S15 IR spectrum of compound 2.

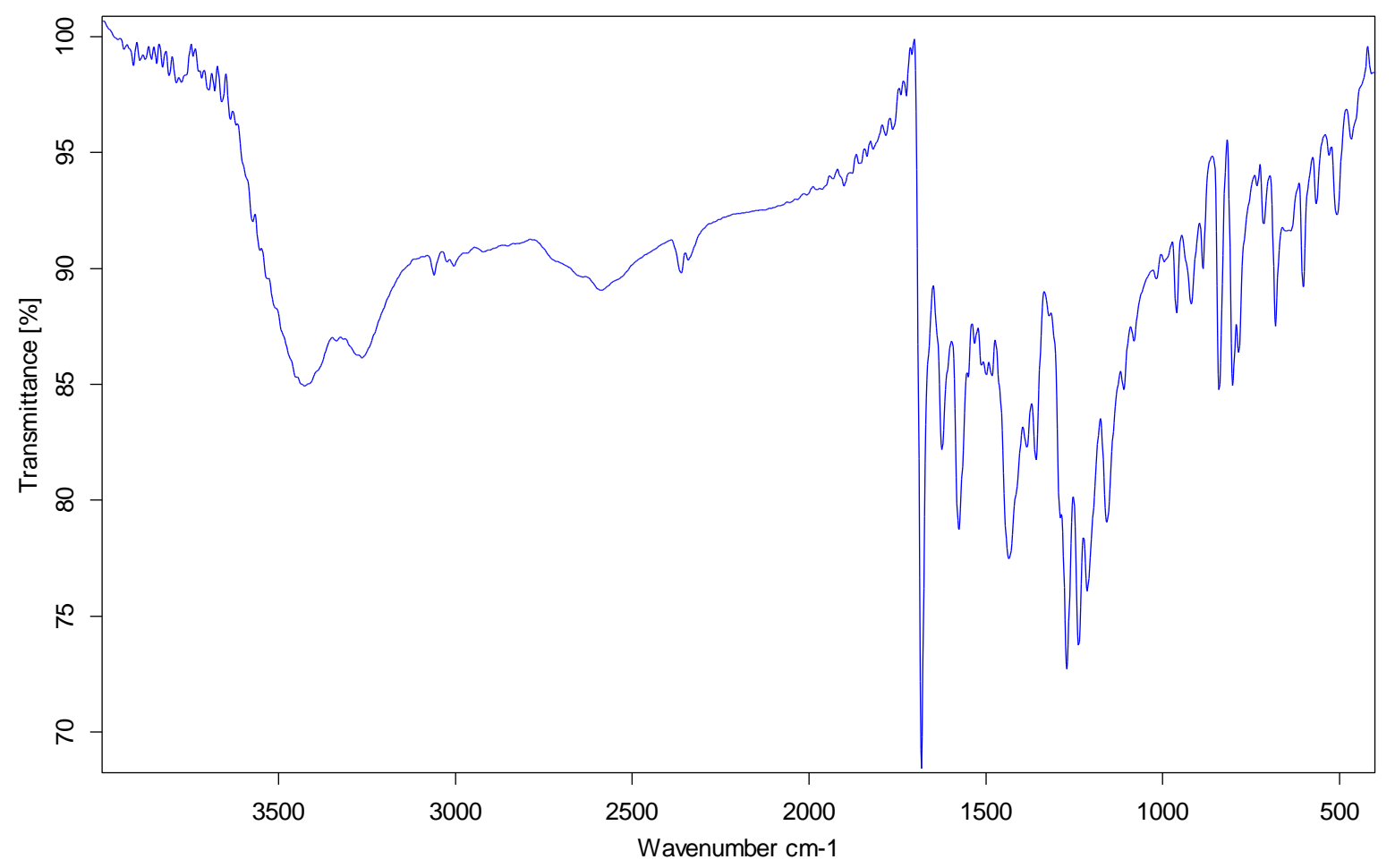

Figure S16 IR spectrum of compound 3.

Table S5 Characteristic stretching bands for 1, 2 and $\mathbf{3}$ found in the FT-IR spectra.

\begin{tabular}{|c|c|c|c|c|c|c|c|c|}
\hline & \multicolumn{8}{|c|}{$\tilde{v} / \mathrm{cm}^{-1}$} \\
\hline & $\begin{array}{c}\mathrm{X}-\mathrm{H}, \\
\mathrm{X}=\mathrm{N} \text { or } \mathrm{O}\end{array}$ & $\begin{array}{c}\mathrm{Car}_{\mathrm{ar}}-\mathrm{H}, \\
\mathbf{C}-\mathrm{H}\end{array}$ & $\mathrm{C}=\mathrm{N}$ & $\mathrm{C}_{\mathrm{ar}}-\mathrm{O}$ & $\mathrm{C}_{\mathrm{ar}}-\mathrm{C}_{\mathrm{ar}}$ & $\mathrm{C}_{\mathrm{ar}}-\mathrm{N}$ & $\mathrm{C}_{\mathrm{ar}}-\mathrm{O}-\mathrm{CH}_{3}$ & $C=0$ \\
\hline 1 & 3442 & 3057,2996 & 1614 & $\begin{array}{c}1255 \\
(1468)\end{array}$ & 1573 & 1357 & 1186 & 1677 \\
\hline 2 & 3458 & 3031,2918 & 1621 & $\begin{array}{c}1462 \\
(1284)\end{array}$ & 1543,1519 & 1357 & & \\
\hline 3 & 3427,3263 & 3061 & 1624 & $\begin{array}{l}1271 \\
1435\end{array}$ & 1576,1547 & 1358 & & 1651 \\
\hline
\end{tabular}


Table S6 Data obtained from the CSD on $d(\mathrm{C} 7-\mathrm{N} 1), d(\mathrm{C} 2-\mathrm{O} 1)$ and $\Phi$ for imines derived from ovan (red data), oOH (blue data) and pOH (green data). Structural motifs used for searches are given in top row.

\begin{tabular}{|c|c|c|c|}
\hline Refcode & $\Phi /^{\circ}$ & $d(\mathrm{C} 7-\mathrm{N} 1) / \AA$ & $d(\mathrm{C} 2-01) / \AA$ \\
\hline AJETUF & 7.451 & 1.274 & 1.355 \\
\hline AVUYUM & 2.564 & 1.270 & 1.351 \\
\hline СІCTOY & 52.176 & 1.285 & 1.354 \\
\hline CIKPIW & 8.522 & 1.281 & 1.369 \\
\hline CUCZUW & 6.873 & 1.278 & 1.355 \\
\hline DUMSEK & 21.242 & 1.278 & 1.349 \\
\hline DUPCIB & 5.594 & 1.312 & 1.288 \\
\hline EKUGEW & 11.941 & 1.301 & 1.346 \\
\hline EKUGIA & 27.010 & 1.271 & 1.335 \\
\hline EVIMEB & 53.933 & 1.271 & 1.347 \\
\hline EVOXIW & 2.661 & 1.302 & 1.299 \\
\hline EVOXIW & 12.944 & 1.288 & 1.325 \\
\hline EVOXIW01 & 2.607 & 1.308 & 1.300 \\
\hline EVOXIW01 & 12.631 & 1.299 & 1.322 \\
\hline EZUWIG & 38.555 & 1.308 & 1.298 \\
\hline EZUWIG & 39.488 & 1.311 & 1.299 \\
\hline EZUWIG & 37.773 & 1.307 & 1.303 \\
\hline EZUWIG & 36.565 & 1.302 & 1.305 \\
\hline FAGSUE & 6.232 & 1.324 & 1.281 \\
\hline FAGSUE & 7.180 & 1.322 & 1.282 \\
\hline FEXRIK & 10.656 & 1.280 & 1.316 \\
\hline FEXRIK & 11.510 & 1.265 & 1.377 \\
\hline FEXRIK01 & 29.200 & 1.283 & 1.348 \\
\hline FEXRIK01 & 30.860 & 1.279 & 1.350 \\
\hline FEXRIK01 & 32.406 & 1.284 & 1.351 \\
\hline FEXRIK01 & 21.672 & 1.272 & 1.358 \\
\hline FEXRIK02 & 32.339 & 1.277 & 1.347 \\
\hline FEXRIK02 & 29.175 & 1.279 & 1.348 \\
\hline
\end{tabular}




\begin{tabular}{|c|c|c|c|}
\hline FEXRIK02 & 33.682 & 1.279 & 1.348 \\
\hline FEXRIK02 & 22.808 & 1.274 & 1.353 \\
\hline FOCCOQ & 7.933 & 1.304 & 1.293 \\
\hline FUGWEK & 31.931 & 1.281 & 1.365 \\
\hline GAWKEV & 12.837 & 1.277 & 1.354 \\
\hline GEPMIY & 29.242 & 1.294 & 1.316 \\
\hline GETTUV & 38.980 & 1.287 & 1.359 \\
\hline GETTUV & 37.742 & 1.287 & 1.360 \\
\hline HAGXUJ & 35.153 & 1.280 & 1.352 \\
\hline HUFLIE & 6.173 & 1.303 & 1.303 \\
\hline HUFLIE & 6.752 & 1.307 & 1.303 \\
\hline HUFLIE & 23.665 & 1.306 & 1.306 \\
\hline IFUMAZ & 5.857 & 1.311 & 1.298 \\
\hline IGECOM & 6.737 & 1.279 & 1.346 \\
\hline IJENAM & 7.837 & 1.275 & 1.337 \\
\hline IJUGUQ & 70.525 & 1.261 & 1.379 \\
\hline KATKAS & 6.142 & 1.319 & 1.291 \\
\hline KUFLUU & 2.094 & 1.279 & 1.346 \\
\hline KUFLUU01 & 28.768 & 1.281 & 1.349 \\
\hline KUFLUU02 & 2.958 & 1.284 & 1.351 \\
\hline KULPOX & 35.459 & 1.274 & 1.366 \\
\hline LOFSII & 5.359 & 1.325 & 1.316 \\
\hline LOFSOO & 6.389 & 1.290 & 1.336 \\
\hline MONGAZ & 25.861 & 1.292 & 1.352 \\
\hline MONGAZ & 29.076 & 1.290 & 1.353 \\
\hline MOYHAL & 44.737 & 1.277 & 1.363 \\
\hline MUBKUQ & 48.110 & 1.278 & 1.362 \\
\hline NEDMUF & 8.786 & 1.306 & 1.286 \\
\hline NEDMUF01 & 3.039 & 1.307 & 1.295 \\
\hline NUQXAA & 5.357 & 1.276 & 1.335 \\
\hline NUQXAA & 4.870 & 1.283 & 1.357 \\
\hline NUQXAA01 & 5.352 & 1.282 & 1.337 \\
\hline NUQXAA01 & 3.233 & 1.294 & 1.362 \\
\hline NUQXAA02 & 3.952 & 1.276 & 1.345 \\
\hline NUQXAA03 & 2.130 & 1.280 & 1.356 \\
\hline POFWOX & 3.099 & 1.319 & 1.286 \\
\hline QOTTEZ & 10.154 & 1.270 & 1.330 \\
\hline QUYGOH & 4.316 & 1.302 & 1.316 \\
\hline REZSIZ & 4.464 & 1.291 & 1.348 \\
\hline REZSIZ01 & 4.437 & 1.288 & 1.348 \\
\hline SAPBAN & 17.832 & 1.270 & 1.346 \\
\hline SOXGAO & 2.809 & 1.28 & 1.356 \\
\hline SUYRIO & 56.787 & 1.279 & 1.375 \\
\hline TEWKOX & 20.885 & 1.309 & 1.288 \\
\hline TEWKOX01 & 21.254 & 1.308 & 1.288 \\
\hline
\end{tabular}




\begin{tabular}{|l|c|c|c|}
\hline UDURER & 6.036 & 1.301 & 1.306 \\
\hline UDURER & 12.979 & 1.299 & 1.311 \\
\hline UNUWEG & 30.588 & 1.285 & 1.350 \\
\hline UNUWEG01 & 30.382 & 1.295 & 1.363 \\
\hline VEFPAZ & 2.926 & 1.296 & 1.299 \\
\hline VIKLAD & 13.211 & 1.303 & 1.296 \\
\hline XEYSOK & 5.086 & 1.293 & 1.324 \\
\hline XOZJEC & 30.404 & 1.284 & 1.354 \\
\hline XOZJUS & 4.599 & 1.297 & 1.333 \\
\hline YALTEK & 15.660 & 1.325 & 1.279 \\
\hline YALTEK & 10.211 & 1.309 & 1.297 \\
\hline YAMZIW & 8.375 & 1.295 & 1.290 \\
\hline YAMZIW & 10.817 & 1.295 & 1.296 \\
\hline YAWXEB & 9.866 & 1.325 & 1.365 \\
\hline YESLUE & 49.024 & 1.287 & 1.356 \\
\hline YODXAS & 13.856 & 1.285 & 1.347 \\
\hline YODXASO1 & 14.421 & 1.281 & 1.355 \\
\hline YODXUM & 54.762 & 1.281 & 1.37 \\
\hline YODXUM01 & 54.644 & 1.275 & 1.368 \\
\hline ZAMLUU & 2.781 & 1.303 & 1.344 \\
\hline ZAMMAB & 10.435 & 1.292 & 1.339 \\
\hline ZAMMEF & 4.473 & 1.305 & 1.323 \\
\hline ZIKNOW & 74.536 & 1.273 & 1.365 \\
\hline & & & \\
\hline
\end{tabular}

2.7. Values of single and double bonds according to tabular values used often for tautomer selection

Table S7 Generally accepted values of single and double bonds according to F. H. Allen et al., J. Chem. Soc. Perkin Trans. II, 1987, S1-S19.

\begin{tabular}{|l|l|l|l|}
\hline \multicolumn{2}{|l|}{ Enol-imine tautomer } & \multicolumn{2}{l|}{ Keto-amine tautomer } \\
\hline Car-C=N-C\# / & 1.279 & C=C-NH-C\# (Nsp planar) / & 1.339 \\
\hline Car-OH (in phenols) / $\AA$ & 1.362 & C=O (in benzoquinone) / & 1.230 \\
\hline
\end{tabular}




\section{REFERENCES}

1 Philips X'Pert Data Collector 1.3e, Philips Analytical B. V. Netherlands, 2001.

2 Philips X'Pert Graphic \& Identify 1.3e Philips Analytical B. V. Netherlands, 2001.

3 Philips X'Pert Plus 1.0, Philips Analytical B. V. Netherlands, 1999.

4 Oxford Diffraction (2003), CrysAlis CCD and CrysAlis RED. Version 1.170., Oxford Diffraction Ltd, Wroclaw, Poland.

5 G. M. Sheldrick, Acta Crystallogr., 2008, A64, 112.

6 L. J. Farrugia, WinGX, J. Appl. Cryst., 1999, 32, 837.

7 Crystallographic data have been deposited with the Cambridge Crystallographic Data Centre, 12 Union Road, Cambridge, CB2 1EZ, UK (fax: +44 1223 336033; e-mail: deposit@ccdc.ac.uk or www: http://www.ccdc.cam.ac.uk). These data can be obtained free of charge from the Director upon request quoting the CCDC deposition numbers 1442712-1442714.

8 L. J. Farrugia, ORTEP-3 for Windows, J. Appl. Cryst., 1997, 30, 565.

9 C. F. Macrae, I. J. Bruno, J. A. Chisholm, P. R. Edgington, P. McCabe, E. Pidcock, L. Rodriguez-Monge, R. Taylor, J.v.d. Streek and P. A. Wood, J. Appl. Crystallogr., 2008, 41, 466.

10 STAR $^{\mathrm{e}}$ Software V10.00., Mettler-Toledo AG, 1993- 2011.

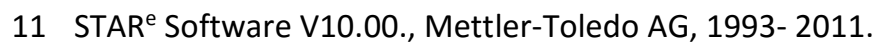

12 PerkinElmer Spectrum v10.4.2.279, PerkinElmer (2014), PerkinElmer Ltd, United Kingdom. 